\title{
Overcoming Chemoresistance: Altering pH of Cellular Compartments by Chloroquine and Hydroxychloroquine
}

\author{
Peter W. Halcrow, Jonathan D. Geiger and Xuesong Chen*
}

Department of Biomedical Sciences, School of Medicine and Health Sciences, University of North Dakota, Grand Forks, ND, United States

Resistance to the anti-cancer effects of chemotherapeutic agents (chemoresistance) is a major issue for people living with cancer and their providers. A diverse set of cellular and inter-organellar signaling changes have been implicated in chemoresistance, but it is still unclear what processes lead to chemoresistance and effective strategies to overcome chemoresistance are lacking. The anti-malaria drugs, chloroquine (CQ) and its derivative hydroxychloroquine (HCQ) are being used for the treatment of various cancers and $C Q$

Edited by:

Mariusz R. Wieckowski,

Nencki Institute of Experimental Biology (PAS), Poland

Reviewed by:

Eisuke Itakura

Chiba University, Japan

Stefano Fais,

National Institute of Health (ISS), Italy

Mojgan Djavaheri-Mergny, Institut National de la Santé et de la

Recherche Médicale (INSERM),

France

*Correspondence: Xuesong Chen

xuesong.chen@und.edu

Specialty section:

This article was submitted to

Signaling,

a section of the journal

Frontiers in Cell and Developmental

Biology

Received: 09 November 2020

Accepted: 18 January 2021

Published: 09 February 2021

Citation:

Halcrow PW, Geiger JD and

Chen X (2021) Overcoming

Chemoresistance: Altering $\mathrm{pH}$

of Cellular Compartments by

Chloroquine and Hydroxychloroquine.

Front. Cell Dev. Biol. 9:627639.

doi: 10.3389/fcell.2021.627639 and $\mathrm{HCQ}$ are used in combination with chemotherapeutic drugs to enhance their anticancer effects. The widely accepted anti-cancer effect of $C Q$ and HCQ is their ability to inhibit autophagic flux. As diprotic weak bases, CQ and HCQ preferentially accumulate in acidic organelles and neutralize their luminal $\mathrm{pH}$. In addition, CQ and HCQ acidify the cytosolic and extracellular environments; processes implicated in tumorigenesis and cancer. Thus, the anti-cancer effects of CQ and HCQ extend beyond autophagy inhibition. The present review summarizes effects of $\mathrm{CQ}, \mathrm{HCQ}$ and proton pump inhibitors on $\mathrm{pH}$ of various cellular compartments and discuss potential mechanisms underlying their $\mathrm{pH}$-dependent anti-cancer effects. The mechanisms considered here include their ability to de-acidify lysosomes and inhibit autophagosome lysosome fusion, to de-acidify Golgi apparatus and secretory vesicles thus affecting secretion, and to acidify cytoplasm thus disturbing aerobic metabolism. Further, we review the ability of these agents to prevent chemotherapeutic drugs from accumulating in acidic organelles and altering their cytosolic concentrations.

Keywords: chloroquine, hydroxychloroquine, chemoresistance, cytosolic pH, endolysosome pH, Golgi pH

\section{INTRODUCTION}

Chemoresistance is a process by which cancer cells evade chemotherapeutic drug-induced cell death. Overcoming chemoresistance represents a major challenge to people living with cancer and their caregivers. A diverse set of cellular and inter-organellar signaling pathways that cancer cells use to promote their own survival and avoid chemotherapeutic agent-induced apoptosis has been described (Senthebane et al., 2017; Zheng, 2017), but the underlying processes responsible for chemoresistance remain unclear and effective strategies to overcome chemoresistance are still lacking.

The progression of cancer and it's resistance to chemotherapy are well-known to be linked to tumor microenvironments (Gerweck et al., 1999). The acid-base balance of microenvironments is 
of particular importance in that $\mathrm{pH}$ is critical for essential biological processes including protein folding, enzyme activity, vesicle trafficking, and inter-organellar signaling. Cancer cell survival is also conditioned on acid-base balance, and a hallmark of tumor microenvironments is the acidic extracellular matrix that is directly linked to a more alkaline cytosolic microenvironment (Swietach et al., 2014). Such acid-base microenvironment adaptations profoundly alter the metabolism of cancer cells that support their special energetic needs. Furthermore, the acid-base microenvironment adaptation occurs in subcellular organelles including endolysosomes (Higgins, 2007; Appelqvist et al., 2013; Sui et al., 2013) and Golgi (Rivinoja et al., 2006, 2009); changes known to contributes to the survival of cancer cells, malignant progression, and the development of chemoresistance.

The anti-malaria drugs, chloroquine (CQ) and its derivative hydroxychloroquine (HCQ), have been used for in the treatment of various cancers often in combination with chemotherapeutic drugs due to their ability to enhance the efficacy of tumor cell killing (Briceño et al., 2003; Boone et al., 2015; Xu et al., 2018). The widely accepted mechanism by which CQ and HCQ exert their anti-cancer effects is their ability to inhibit autophagic flux (Amaravadi et al., 2011; Ye et al., 2016; Mauthe et al., 2018). As diprotic weak bases, CQ and HCQ preferentially accumulate in acidic organelles (endolysosomes and Golgi) and neutralize their luminal pH. However, simultaneously, CQ and HCQ acidify the cytosol and de-acidify the extracellular environment (Xia et al., 2018; Halcrow et al., 2019a,b). Thus, the anti-cancer effects of CQ and HCQ might extend beyond autophagy inhibition.

To strengthen the application and possible use of CQ and HCQ as adjuvant therapies to overcome chemoresistance, it is important to understand better the effects of CQ and HCQ on $\mathrm{pH}$, inter-organellar interactions, and other cellular processes from a subcellular perspective. Accordingly, the present review will summarize the microenvironment $(\mathrm{pH})$ adaptation of cancer cells and discuss potential mechanisms underlying acid/basedependent anti-cancer effects of CQ and HCQ. These include their ability to de-acidify lysosomes and inhibit autophagosome lysosome fusion, to de-acidify Golgi apparatus and secretory vesicles thus affecting secretion, and to acidify the cytoplasm thus disturbing aerobic metabolism. Further, we will discuss their ability to prevent chemotherapeutic drugs from accumulating in acidic organelles thus increasing cytosolic concentrations of anti-cancer drugs.

\section{TUMOR MICROENVIRONMENT}

\section{Extracellular Microenvironment}

Observed by Warburg and Pasteur in aerobic glycolysis and hypoxia, the physiological $\mathrm{pH}$ of the extracellular microenvironment of normal tissue ( $\mathrm{pH} 7.4)$ becomes acidic $(\mathrm{pH}$ 6.5) in tumor microenvironments due to the excretion of lactic acid (Bailey et al., 2012). This acidification of the extracellular microenvironments around tumors not only enhances the activity of proteinases such as metalloproteinase and released lysosomal enzymes, but also affects transcription via activation of signal transduction across the plasma membrane, and thus augments the malignancy and aggression of cancer (Schornack and Gillies, 2003; Gatenby et al., 2006; Moellering et al., 2008; Hashim et al., 2011; Kato et al., 2013). Acidification of the extracellular microenvironment also creates an obstacle of the proton-gradient at the plasma membrane that reduces the uptake of chemotherapeutic agents such as mitoxantrone and topotecan, and thus generates tumors resistant to chemotherapy and immunotherapy (Thews et al., 2006; Kato et al., 2013; Pilon-Thomas et al., 2016).

\section{Cytosol}

The cytosolic $\mathrm{pH}$ of normal cells ( $\mathrm{pH}$ 6.99-7.2) becomes more alkaline ( $\mathrm{pH} 7.12-7.65)$ in cancer cells (Oberhaensli et al., 1986; Ng et al., 1989; Vaupel et al., 1989; Baghdadi, 2017). The acidic nature of the extracellular environment and a more alkaline cytosolic microenvironment in cancer cells generates a proton-gradient across the plasma membrane that becomes a source of proton-motive energy, and cancer cells use this energy to synthesize phosphate bonds (pyrophosphate) from free phosphate and generate ATP independently of glycolysis and mitochondrial ATP. This cellular phenomenon of the proton gradient across plasma membranes further stimulates the energy needs of cancer cells and stimulates tumor cell proliferation (Dhar et al., 2015).

In cancer cells, the metabolism mechanisms switch to glycolysis for ATP production; a process first described by Otto Warburg in 1924 that became known as the "Warburg effect." Regardless of the availability of $\mathrm{O}_{2}$, cancer cells increasingly convert glucose into lactate and utilize the glucose metabolites to accelerate cell proliferation at the expense of generating two molecules of ATP per molecule of glucose. Tumors, which demand high levels of energy, make up for this ATP loss by going through glycolysis much faster and more often than do normal cells. Indeed, Warburg hypothesized that tumor formation originated due to irreversible damage to mitochondrial oxidative phosphorylation. Under normal oxygen tension conditions, Warburg observed normal cells produced most of their energy from mitochondrial respiration while over $50 \%$ of the energy generated in cancer cells originated in the cytosol from glycolysis and the remainder from mitochondrial respiration. However, the reliance of cancer cells on glycolysis for most of their energy is not due to lack of oxygen, because even in the presence of adequate oxygenation cancer cells still operate mainly via glycolysis (Fadaka et al., 2017).

An increase in cytosolic pH (alkalization) can shift metabolism from oxidative phosphorylation to glycolysis under aerobic conditions in cancer cells (Reshkin et al., 2000, 2013; Nagata et al., 2011). The Warburg effect can be explained by an increase in cytosolic $\mathrm{pH}$ in cancer cells. The alkalinization of the cytosolic microenvironment initiates aerobic glycolysis (Reshkin et al., 2000) and hydrogen ions may be one of the most significant factors responsible for determining how cancer cells obtain energy. Even in the presence of adequate oxygen, an alkaline cytosolic $\mathrm{pH}$ drives aerobic glycolysis, and an acidic intracellular $\mathrm{pH}$ drives oxidative phosphorylation (OXPHOS) (Harguindey et al., 2005; López-Lázaro, 2010). Thus, OXPHOS and glycolysis are oppositely $\mathrm{pH}$ sensitive. Furthermore, an alkaline cytosolic $\mathrm{pH}$ activates the key glycolytic enzyme phosphofructokinase 
and inhibits gluconeogenesis (Trivedi and Danforth, 1966; Harguindey et al., 1979). In addition, an alkaline cytosolic pH inhibits OXPHOS and pyruvate entry into the Krebs cycle (Relman, 1972). Therefore, damaged mitochondrial respiration is not the primary cause of cancer, as Warburg suggested, but the main cause of aerobic glycolysis in cancer cells appears to be a disruption of the acid-base homeostasis within cells (Alfarouk et al., 2014). The $\mathrm{Na}^{+} / \mathrm{H}^{+}$exchanger isoform 1 (NHE1) proton transporter is known to be specifically involved in cellular acidbase balance in cancer cells, where it contributes to cytosolic $\mathrm{pH}$ homeostasis, cell transformation, proliferation, tumor growth, invasion, activation of the metastatic process, and resistance to chemotherapy (Cardone et al., 2005; Stock et al., 2008; Reshkin et al., 2013). This helps explain the vast literature on targeting NHE1 in cancer through the use of so-called proton pump inhibitors.

\section{Nucleus}

Equivalent to the cytosolic microenvironment, the nuclear microenvironment in normal cells is slightly more alkaline $(\mathrm{pH}$ 7.55-7.88) than that of the cytosol (Cody et al., 1993; Seksek and Bolard, 1996; Masuda et al., 1998). However, little is known about how nuclear $\mathrm{pH}$ affects nuclear biology. Given the inherent affinity of nucleic acids and nuclear proteins for protons, it is predicated that nuclear $\mathrm{pH}$ alteration is likely to influence the activity of transcription factors and thus DNA replication (Hulikova and Swietach, 2016). Furthermore, chemotherapeutic drugs are designed to often work by targeting DNA processes and rapidly proliferating cells. The nucleus represents a major site where most chemotherapeutic compounds are likely to be effective in preventing DNA replication (Patel and Patel, 2012). Altered nuclear $\mathrm{pH}$ is also likely to alter the levels of nucleus-targeting chemotherapeutic compounds and affects their effectiveness in preventing DNA replication for cancer repression. However, presently unclear is the extent to which nuclear $\mathrm{pH}$ is changed in cancer cells.

\section{Endolysosomes}

Endosomes and lysosomes (endolysosomes) represent a dynamic system of organelles exhibiting morphological and functional heterogeneity as well as complex interactions with other organelles. A hallmark of the endolysosome system is their acidic luminal pH (Matsuo et al., 2004; Huotari and Helenius, 2011; Mindell, 2012; Mcguire et al., 2017; Prasad and Rao, 2018), where early endosomes have a luminal $\mathrm{pH}$ of 6.06.6 , late endosomes have a luminal $\mathrm{pH}$ of $\sim 5.0$, and the lumen of lysosomes is most acidic with a $\mathrm{pH}$ as low as $\sim 4.5$. The acidic environment is critical for the activity of up to 60 different $\mathrm{pH}$ sensitive hydrolytic enzymes including proteases, lipases and nucleases (De Duve, 2005). Although no direct measurements of alterations in endolysosome $\mathrm{pH}$ of cancer cells has been reported, changes in endolysosome volume and subcellular localizations have been reported during oncogenic transformation (Kirkegaard and Jaattela, 2009; Kallunki et al., 2013; Fennelly and Amaravadi, 2017), and such morphological changes indicate a functional adaption of endolysosomes including alterations in endolysosome $\mathrm{pH}$, which occurs in cancer biology.

Classically known as garbage processing centers, endolysosomes are responsible for the degradation of extracellular macromolecules and membrane components as well as long-lived intracellular proteins and obsolete organelles. Up-taken into endosomes via endocytosis, extracellular macromolecules and membrane components can either be trafficked through early endosomes to recycling endosomes, which mediates receptor recycling to the plasma membrane or Golgi apparatus, or can even transition to late endosomes and fusion with lysosomes (Bright et al., 2005; De Duve, 2005; Luzio et al., 2007; Huotari and Helenius, 2011). The acidic pH of lysosomes and their $\mathrm{pH}$-sensitive hydrolases are critical for the degradation of cytosolic proteins and organelles via the formation of autophagosomes, which are then fused with late endosomes/lysosomes; the so-called "self-eating" or autophagy, which is essential for cell homeostasis and development (Ohsumi, 2014; Spiering, 2019).

During autophagy, engulfed cytosolic macromolecules and organelles are broken down into building blocks used for metabolism and to produce energy and build new proteins, lipids, sugars, and amino acids. As such, under starvation conditions, autophagy becomes an internal source of nutrients and energy, promoting survival under harsh conditions as it fuels metabolism for cells under stress. It is known that harsh conditions, such as hypoxia, nutrient deprivation, and oxidative stress, exist in tumor microenvironments, thus, cancer cells exploit autophagy to survive. The number of autophagosomes is increased in tumors under hypoxic regions, and knocking out autophagyregulating genes results in tumor cell death; thus, cancer cells exploit autophagy to survive (Mathew et al., 2007; Cheng et al., 2013). To avoid cell death, tumor cells can reprogram themselves metabolically in order to engage autophagy as a source of energy and survive (Deberardinis et al., 2008; Lozy and Karantza, 2012). In addition to the classical degradation role, endolysosomes control a variety of essential physiological functions including antigen processing, membrane repair, nutrient sensing, and ion homeostasis (Christensen et al., 2002; Casey et al., 2010; Xu and Ren, 2015; Pu et al., 2016); all of which can contribute to cancer progression.

Endolysosomes also play an important role in chemoresistance (Zhitomirsky and Assaraf, 2016; Geisslinger et al., 2020; Hrabeta et al., 2020). The acidic environment of endolysosomes facilitates luminal accumulation of lipophilic, weakly basic chemotherapeutic drugs. Hydrophobic weak-base chemotherapeutic drugs are predominately accumulated in endolysosomes via passive diffusion along the $\mathrm{pH}$ gradient or are actively transported across membranes into the endolysosome lumen by P-glycoproteins embedded in endolysosome membranes (Yamagishi et al., 2013; Al-Akra et al., 2018). Upon entering endolysosome lumen, weak-base chemotherapeutic drugs undergo protonation and are trapped in endolysosomes. Once trapped inside endolysosome, weak-base chemotherapeutic drugs can no longer reach the cytosolic compartment and the nucleus to exert their anticancer effects; processes linked to chemoresistance (Zhitomirsky and Assaraf, 2017). Such 
trapped weak-base chemotherapeutic drugs can directly alter endolysosome structure and function, such as alteration in endolysosome $\mathrm{pH}$ and influence endolysosome-dependent signaling that results in enhanced endolysosome biogenesis (Fassl et al., 2020). Alternatively, trapped weak-base chemotherapeutic drugs can be eliminated from the cell via an increase in the lysosomal exocytosis cellular process, which is known to be directly due to these drugs themselves (Hrabeta et al., 2020).

\section{Golgi Apparatus and Secretory Vesicles}

Golgi apparatus are mildly acidic with luminal $\mathrm{pH}$ values ranging from 6.7 at cis-Golgi to 6.0 at trans-Golgi (Kellokumpu, 2019). Secretory vesicles are more acidic with luminal $\mathrm{pH}$ ranging from 5.2 to 5.7 (Demaurex, 2002; Paroutis et al., 2004). The acidic environments in Golgi are critical for processing, sorting, and trafficking of proteins and lipids destined for secretion, membranes, and organelles. Golgi $\mathrm{pH}$ in malignant cells is more alkaline than non-malignant cells (Rivinoja et al., 2006, 2009) and anion channels regulate Golgi pH (Maeda et al., 2008; Maeda and Kinoshita, 2010). Alkalization of Golgi lumen results in defects in post-translational modifications and processing of secreted proteins; glycosylation is $\mathrm{pH}$-sensitive (Axelsson et al., 2001; Maeda et al., 2008; Maeda and Kinoshita, 2010) and a slight increase in $\mathrm{pH}$ results in decreased glycosylation (Rivinoja et al., 2006). Altered glycosylation is a hallmark of cancer phenotypes (Meezan et al., 1969) and promotes tumorigenesis and metastasis (Hakomori, 2002; Häuselmann and Borsig, 2014; Peixoto et al., 2016). The loss of the O-glycosyltransferase heteromers or enzyme mis-localization are thought to be the two main reasons for the $\mathrm{pH}$-dependent glycosylation changes seen in cancer cells (Jass et al., 1994; Kuhns et al., 1995; Hakomori, 2002; Kellokumpu, 2019). With respect to the sorting and trafficking of proteins and lipids, alkalization of Golgi can impair anterograde transport from Golgi to secretary vesicles (Chanat and Huttner, 1991), retrograde transport from Golgi back to the endoplasmic reticulum (Palokangas et al., 1998), the delivery of lysosomal hydrolases to lysosomes via mannose-6-phosphate receptor (Ghosh et al., 2003; Kokkonen et al., 2004), the integrity of Golgi itself (Linstedt et al., 1997; Puri et al., 2002), and the sorting and proteolytic maturation of prohormones in secretory granules (Schmidt and Moore, 1995); all of which contribute to the malignant nature of cancer cells.

\section{CHLOROQUINE DE-ACIDIFIES ACIDIC ORGANELLES AND ACIDIFIES THE CYTOSOL}

As diprotic weak-base drugs, $\mathrm{CQ}\left(\mathrm{pK}_{\mathrm{a} 1}=8.1, \mathrm{pK}_{\mathrm{a} 2}=10.2\right)$ and HCQ $\left(\mathrm{pK}_{\mathrm{a} 1}=8.3, \mathrm{pK}_{\mathrm{a} 2}=9.7\right)$ are present in protonated and unprotonated forms. Unprotonated forms of CQ and HCQ can diffuse freely across membranes into the lumen of acidic endolysosomes and Golgi. Once protonated, CQ and HCQ become trapped in the lumen of these acidic organelles (Martin et al., 2009; Solomon and Lee, 2009). The driving force for intraluminal accumulation of CQ and HCQ is proportional to the square of the hydrogen ion gradient. Thus, the driving force is much larger than that of a monoprotic weak base like ammonia chloride, which is proportional to the hydrogen ion gradient (De Duve et al., 1974; Roos and Boron, 1981). Thus, CQ and HCQ are preferentially concentrated in and neutralize the acidic $\mathrm{pH}$ of organelles including endolysosomes (Homewood et al., 1972; Schlesinger et al., 1988; Dunmore et al., 2013; Khan et al., 2019) and Golgi (Rivinoja et al., 2006, 2009; Kellokumpu, 2019). In addition, chloroquine acidifies the cytosol by $0.2-0.4 \mathrm{pH}$ units within $1 \mathrm{~h}$ of drug exposure (Xia et al., 2018). Therefore, CQ and HCQ can de-acidify acidic organelles as well as acidify the cytoplasm; effects linked to overcoming chemoresistance.

\section{CQ-INDUCED INHIBITION OF AUTOPHAGIC FLUX ENHANCES THE EFFICACY OF CHEMOTHERAPEUTIC DRUGS}

Tumor cells can be reprogrammed metabolically in order to engage autophagy as a source of energy and survival (Deberardinis et al., 2008; Lozy and Karantza, 2012). CQ and HCQ can directly inhibit the formation of autolysosomes (Boya et al., 2005; Jahreiss et al., 2008; Klionsky et al., 2016). More specifically, CQ and HCQ increase the $\mathrm{pH}$ of lysosomes and inhibit the activity of the hydrolase enzymes, which inhibits the fusion of autophagosomes with lysosomes and thus blocks the degradation of engulfed macromolecules and damaged organelles (Amaravadi et al., 2011; Ye et al., 2016; Mauthe et al., 2018). CQ treatment alone has been shown to inhibit cancer cell growth, as well as enhance apoptosis through the inhibition of autophagic flux (Ye et al., 2016). Furthermore, CQ-induced inhibition of autophagic flux can enhance the apoptotic efficacy of anticancer drugs (Cheng et al., 2013). As a pro-survival mechanism, autophagy promotes cancer cell fitness under stressful conditions, as well as acts as a protective mechanism for tumor cells against chemotherapy and promotes drug resistance (White and Dipaola, 2009; Al-Akra et al., 2019). Thus, CQ-induced inhibition of autophagic flux could enhance the cytotoxicity of temozolomide and increase radiosensitivity in glioblastoma (Taylor et al., 2018). It also has been shown that autophagy activation contributes to cancer cells resistant to cisplatin due to aquaporin 3 (AQP3) over-expression, and CQ-induced autophagy inhibition reverses the chemoresistance caused by AQP3 over-expression (Dong et al., 2016).

\section{CQ-INDUCED DE-ACIDIFICATION PREVENTS ENDOLYSOSOME ACCUMULATION OF CHEMOTHERAPEUTIC DRUGS AND INCREASES THEIR CONCENTRATIONS IN THE CYTOSOL AND NUCLEUS}

Hydrophobic weak-base chemotherapeutic drugs accumulate in endolysosomes (Jansen et al., 1999; Kaufmann and Krise, 2007; 
Adar et al., 2012; Zhitomirsky and Assaraf, 2016), de-acidify endolysosomes (Kazmi et al., 2013), promote increased lysosomal exocytosis (Zhitomirsky and Assaraf, 2017), and enhance endolysosome biogenesis (Zhitomirsky and Assaraf, 2015); all of which contributes to the development of chemoresistance (Jansen et al., 1999; Gotink et al., 2011; Zhitomirsky and Assaraf, 2015). These cellular phenomena between weak-base chemotherapeutic drugs and endolysosomes brings to the forefront the critical role that endolysosomes play in the development of chemoresistance in cancer cells (Figure 1A).

As diprotic weak-base drugs, CQ and HCQ are preferentially concentrated in endolysosomes (Morissette et al., 2004; Solomon and Lee, 2009; Marceau et al., 2012), where they neutralize the acidic luminal $\mathrm{pH}$ (Schlesinger et al., 1988; Khan et al., 2019), induce enlargement of endolysosomes (Yoon et al., 2010; Mauthe et al., 2018), alter the positioning of endolysosomes from perinuclear to the periphery of cells (Johnson et al., 2016; Datta et al., 2019), and lead to lysosome membrane permeabilization (Circu et al., 2017; Sironi et al., 2019; Khan et al., 2020). Thus, CQ-induced endolysosome de-acidification alone could lead to cytotoxic effects in cancer cells. Also, CQ-induced endolysosome de-acidification could result in accumulation and aggregation of un-degraded substrates and atypical cleavages that lead to the generation of toxic intermediates (Caporaso et al., 1992; Hui et al., 2019). Furthermore, CQ-induced lysosomal membrane permeabilization leads to the translocation of lysosomal contents (e.g., cathepsins) to the cytoplasm, which results in the induction of mitochondria damage and cell death (Boya, 2012; Wang et al., 2018).

Interestingly, HCQ pretreatment at a low concentration (5 $\mu \mathrm{M})$ enhances the sensitivity of tumor cells to doxorubicin (Li et al., 2018). At this low concentration, HCQ caused no cytotoxicity, which indicates that the diprotic weak-base HCQ can function as a sensitizing agent to enhance the intended purpose of chemotherapeutic agents without killing cells directly. Moreover, HCQ pre-treatment enhanced the effects of other chemotherapeutic agents, including paclitaxel, mitomycin C, and cisplatin, in inhibiting tumor proliferation. Also, increased entry of doxorubicin across the plasma membrane into the cytoplasm in the A549 cancer cell line was observed with HCQ pre-treatment (Li et al., 2018). Most importantly in this same study, the accumulation of doxorubicin in lysosomes was blocked when cells were pre-treated with HCQ. These findings indicate that HCQ and CQ enhance the sensitivity of cancer cells to chemotherapeutic drugs by increasing the concentration of chemotherapeutic compounds across the plasma membrane into the cytoplasm, preventing accumulation of chemotherapeutic drugs in lysosomes, and thus increase their concentrations in cytosolic and nuclear compartments; the sites where chemotherapeutic effects occur (Figure 1B; Liu et al., 2014; Rebecca and Amaravadi, 2016; Ruiz et al., 2016; Tang et al., 2016; Yan et al., 2018).

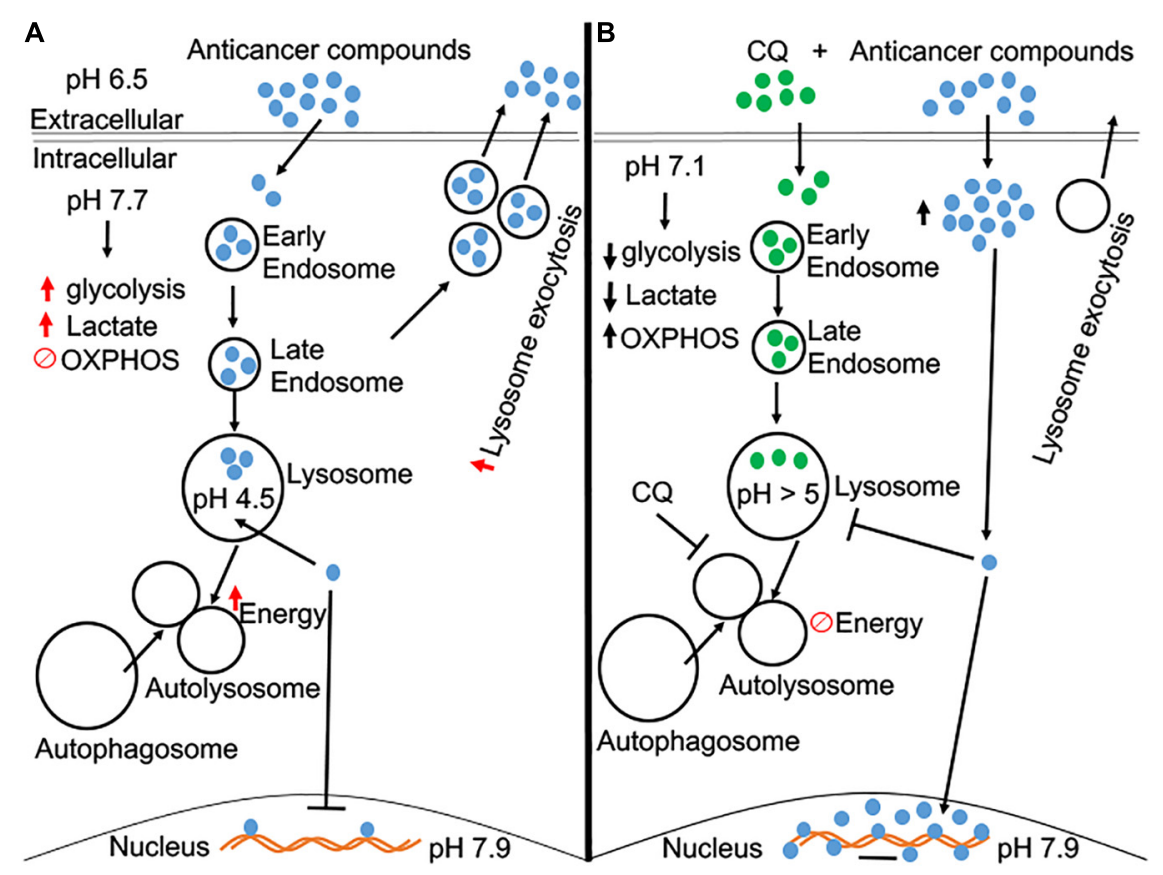

FIGURE 1 | A schematic diagram of CQ pre-treated in overcoming chemoresistance. (A) Beside acidic extracellular microenvironment, tumor cells have a slightly alkaline cytosolic microenvironment, which leads to an increase in aerobic glycolysis. Anti-cancer compounds (many of them are weak bases) tend to accumulate in acidic organelles, like endolysosomes, and increase exocytosis of these compounds back into the extracellular matrix. Thus, the designated effect of these anti-cancer compounds is futile, and the cell becomes resistant to these weak-base anti-cancer compounds. (B) Pre-treatment of CQ acidifies the cytosolic microenvironment and may reverse the increase of aerobic glycolysis as occurs in cancer cells. Pre-treatment of CQ de-acidifies endolysosomes and inhibits autophagic flux. CQ-induced endolysosome de-acidification prevents the accumulation of anti-cancer compounds in endolysosomes and increases their concentration in the cytosol and nucleus, the sites where anti-cancer compounds exert their anti-cancer effects. 


\section{CQ-INDUCED CYTOSOLIC ACIDIFICATION DISTURBS AEROBIC METABOLISM AND REPLICATION}

Hydrogen ions are significant factors in determining how cancer cells obtain energy. The slight cytosolic alkalization, as occurs in cancer cells, can initiate aerobic glycolysis in cancer cells (Reshkin et al., 2000, 2013; Nagata et al., 2011), and thus contribute to the Warburg effect and profoundly affecting cancer cell metabolism. Reversing the $\mathrm{pH}$ gradient hallmark of cancer metabolism from the alkaline cytosolic $\mathrm{pH}$ back towards a slightly acidic $\mathrm{pH}$ could disable cell proliferation and tumor growth (Persi et al., 2018). As such, the ability of CQ to acidify the cytosol and reverse the slightly alkaline cytosolic $\mathrm{pH}$, as present in cancer cells, back to physiological levels could help overcome chemoresistance, which represents a novel target of interest. It is currently not clear how CQ acidifies the cytosolic microenvironment.

\section{CQ-INDUCED GOLGI DE-ACIDIFICATION AND CHEMORESISTANCE}

Golgi luminal pH is slightly increased in cancer cells, and such change in Golgi luminal $\mathrm{pH}$ can alter glycosylation, a hallmark of cancer phenotypes (Meezan et al., 1969). As diprotic weakbase drugs, CQ and HCQ are also concentrated in and neutralize the $\mathrm{pH}$ of acidic Golgi (Kellokumpu, 2019), and induce marked dilatation of the Golgi cisternae (Thorens and Vassalli, 1986). Little is known about how CQ affects the progression of a cancer cell that is already exhibiting an elevated luminal $\mathrm{pH}$ of Golgi. There is evidence indicating that CQ not only results in deficits in glycosylation (Rivinoja et al., 2006), but also leads to deficits in the formation of functional transport vesicles and impaired ability of budding vesicles to pinch off and form functional transport vesicles (Oda and Ikehara, 1985; Hiebsch et al., 1991). Such effects of CQ could potentially disturb the progression of cancer cells, which warrants further investigation. Furthermore, CQ-induced Golgi de-acidification can also change distribution patterns of mannose-6-phosphate receptors and decrease the delivery of lysosomal enzymes into lysosomes (Brown et al., 1984), which could, in another way, inhibit autophagic flux and enhance the apoptotic efficacy of chemotherapeutic drugs.

\section{CQ-INDUCED DE-ACIDIFICATION OF ACIDIC ORGANELLES AND IMMUNOMODULATORY PROPERTIES}

CQ and HCQ also exhibit immunomodulatory properties and are used clinically for the treatment of rheumatoid arthritis, systemic lupus erythematosus, and other inflammatory rheumatic diseases (Gotoff, 1968; Panayi et al., 1973; Schrezenmeier and Dorner, 2020). Although not fully understood, CQ- and HCQ-induced de-acidification of acidic organelles, including endolysosomes and Golgi, in immune cells could, at least in part, contribute to their immunomodulatory effects. Given that lysosomal degradation of endocytosed or autophagocytosed proteins plays an important role in antigen processing and $\mathrm{MHC}$ class II presentation (Lotteau et al., 1990; Munz, 2016), CQ- and HCQ-induced endolysosome de-acidification could inhibit MHC class II expression, antigen presentation and immune activation (Belizaire and Unanue, 2009). In addition, activation of toll-like receptor (TLR) signaling, and production of pro-inflammatory cytokines has been linked to binding of RNA and DNA to TLR7 and TLR9 in endosomes (Ewald et al., 2008). It is likely that CQ- and HCQ-induced endolysosome de-acidification could interfere with the binding of RNA and DNA to TLR7 and TLR9, and thus inhibit TLR signaling and the production of pro-inflammatory cytokines (Kuznik et al., 2011; Schrezenmeier and Dorner, 2020). Furthermore, CQ- and HCQ-induced deacidification of endolysosomes and Golgi could contribute to their inhibitory effects on the release of various pro-inflammatory cytokines such as IL-1, IFN $\alpha$, and TNF $\alpha$ (Savarino et al., 2003; Jang et al., 2006). For example, de-acidifying Golgi by CQ and HCQ blocked the conversion of pro-TNF $\alpha$ to its soluble mature form in Golgi (Jeong and Jue, 1997; Jang et al., 2006). CQand HCQ-induced de-acidification of endolysosomes and Golgi reduced the secretion of pro-inflammatory cytokines such as TNF- $\alpha$, IL-1 $\beta$, and IL-6 (Savarino et al., 2003; Jang et al., 2006); both Golgi (Murray and Stow, 2014) and endolysosomes (Carta et al., 2013; Zhang et al., 2015) are involved in cytokine release. Such anti-inflammatory effects may exacerbate the progression of cancer. On the other hand, CQ-induced lysosome deacidification and amelioration of the tumor microenvironment has been implicated in its immunomodulatory effect, in which CQ mediates its antitumor efficacy via resetting tumor-associated macrophage from the M2 to the M1 phenotype (Chen et al., 2018; Li et al., 2018).

\section{CQ AND HCQ EFFICACY BASED ON TUMOR STATUS}

Effectiveness of CQ and HCQ in overcoming chemoresistance is also affected by specific protein expression and autophagic status of various tumors, which needs to be considered in drugassisted therapy. As discussed, there has been much interest in targeting autophagy in cancer therapy based on preclinical findings (Guo et al., 2011; Yang et al., 2011). Even though CQ is under evaluation in clinical trials to target autophagy in cancer therapy, a current study demonstrated in oncogenic KRAS-dependent tumors that CQ was synergistic with tyrosine kinase inhibitors but not with ATG7 deficiency. These findings indicate that inhibition of autophagy may not be a relevant mechanism of action for CQ in certain cancer types (Eng et al., 2016). Furthermore, certain cancer types like acute myeloid leukemia (AML) render autophagy dispensable such that CQbased treatment is ineffective in vivo due to limited drug efficacy in the blood (Chen et al., 2017). Thus, autophagic status of tumor cells may alter the effectiveness of CQ and HCQ. In addition, activation of the p53 pathway is a crucial strategy in targeting certain cancer types like glioblastoma, and CQ alone activates the p53 pathway and suppresses growth of glioma cells as well as metastatic tumor growth (Kim et al., 2010; Burikhanov et al., 2017). Adversely, HCQ accelerates tumor formation in oncogenic 
KRAS-dependent tumors that are p53 deficient (Rosenfeldt et al., 2013). Thus, tumor specific protein expression may alter the effectiveness of CQ and HCQ.

\section{LYSOSOME MEMBRANE PERMEABILITY AND CHEMORESISTANCE}

An interesting and developing mechanism in chemoresistant therapy is lysosomal membrane permeability (LMP). Chemotherapeutic drug deposition into lysosomes generates chemoresistant cancer cells. Studies demonstrate that uptake of LMP inducers leads to cell death through ROS that disintegrate the membrane of lysosomes, thus, releasing entrapped chemotherapy agents to localize to the nucleus and induce cytotoxic effects (Seebacher et al., 2016). CQ enhances the production of endogenous nitric oxide that inhibits the activity of p-glycoprotein, which then localizes chemotherapy agents to the cytosol and nucleus and promotes cytotoxic effects in hepatic cancer (Li et al., 2017; Salaroglio et al., 2018). Furthermore, CQ with gemcitabine increases LMP and causes cathepsins to be released into the cytoplasm, which is associated with apoptosis (Bjørkøy et al., 2009; Fu et al., 2018; Sharapova et al., 2018).

\section{ADVERSE EFFECTS OF CQ AND HCQ}

Once trapped in acidic organelles, CQ and HCQ can only be extruded by exocytosis and/or through the multidrug resistance protein p-glycoprotein (Yamagishi et al., 2013; Zhitomirsky and Assaraf, 2016, 2017). Given their ability to de-acidify acidic organelles and acidify cytosolic pH, CQ and HCQ may disturb many key aspects of cell biology such as organellar biology and inter-organellar signaling. However, decades of clinical usage have shown that CQ and HCQ are relatively safe drugs. Especially, CQ and HCQ have been used during pregnancy in patients with autoimmune disorders, and recent systematic reviews and meta-analyses suggest that maternal use of HCQ during pregnancy does not increase risk of major congenital malformations (Gotoff, 1968). The reported tissue side effects of CQ and HCQ, such as retinopathy (Marmor et al., 2016; Nguyen et al., 2018), cardiomyopathy (Yogasundaram et al., 2018), neuromyotoxicity (Estes et al., 1987), and harmful effects on sperm quality (Leroy et al., 2015), are likely due to abnormal accumulation of these drugs in tissues with chronic use at a higher dosage (Adelusi and Salako, 1982; Chandler et al., 2020).

\section{CQ AND HCQ AS ADJUVANT CANCER THERAPY IN CLINICAL TRIALS}

Preclinical studies support of the use of CQ and HCQ in anticancer therapy, especially in combination with chemotherapeutic drugs because they are able to sensitize tumor cells to a variety of chemotherapeutic drugs and enhance their efficacy in tumor cell killing. Currently, clinical trials are evaluating the activity of CQ and HCQ in different cancer types and in combination with various standard treatments. Many of these clinical studies are designed to assess their anti-cancer effects as inhibitors of autophagic flux. Findings from these clinical studies are in favor of the repurposing of CQ and HCQ as adjuvant cancer therapies (Sotelo et al., 2006; Barnard et al., 2014). A metaanalysis of clinical trials (Xu et al., 2018) indicates that CQ and HCQ, as autophagy-inhibitor-based therapy enhances a better treatment response and outcome when compared to chemotherapy or radiation therapy alone without inhibiting autophagy. Although many clinical trials are underway to further evaluate the effectiveness of CQ and HCQ used in combination with chemotherapeutic drugs, a number of trials have been completed and show beneficial effects in different cancer types (Table 1). One clinical trial for patients with glioblastoma, which has a poor-prognosis of survival, found that patients treated with CQ in combination with chemotherapy and radiation had a significantly longer survival (Briceño et al., 2003). Another clinical study examined the effects of HCQ on patients with pancreatic adenocarcinoma as adjuvant therapy to gemcitabine. In this study, patients who had more than a $51 \%$ increase in the autophagy marker LC3-II in their circulating peripheral blood mononuclear cells showed improvement in

TABLE 1 | A brief list of completed clinical trials on the efficacy of CQ and HCQ in combination with chemotherapeutic drugs.

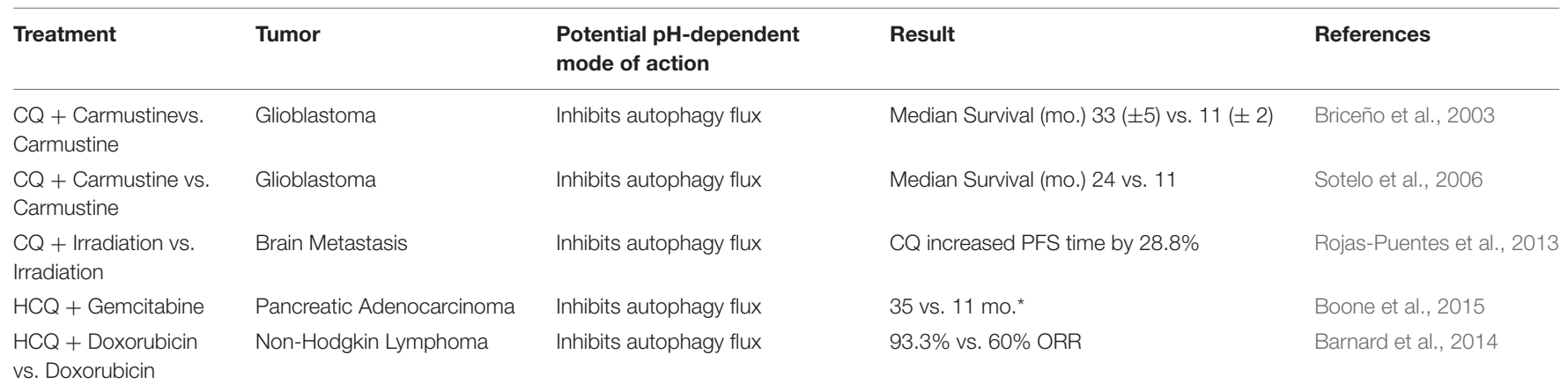

*Patients who had more than a 51\% increase in the autophagy marker LC3-Il in circulating peripheral blood mononuclear cells was 35 months vs. who did not at 11 months.

ORR, Overall Response Rate; PFS, Progression Free Survival. 
disease-free survival and in overall survival (Boone et al., 2015). One other clinical study found that treatment with CQ plus whole-brain irradiation improved the control of metastases in the brain; however, in this particular study CQ did not improve the response rate or the overall survival (Rojas-Puentes et al., 2013). The anti-cancer effects of CQ and HCQ being tested in different cancer types at different stages, and in combination with various chemotherapeutic treatment, may contribute to the inconsistencies in clinical findings. It should be noted that in addition to lysosome de-acidification and inhibition of autophagic flux, CQ and HCQ affect many other aspects of the tumor microenvironment. Thus, larger and more definitive studies of CQ and HCQ as adjuvant cancer therapy are warranted (Verbaanderd et al., 2017).

\section{PROTON PUMP INHIBITORS}

Proton pump inhibitors (PPI), with varying efficacies, enhance the effectiveness of chemotherapeutic agents against tumor growth and metastasis (Fais, 2010, 2015; Taylor et al., 2015; Lugini et al., 2016; Spugnini and Fais, 2017). Similar to CQ and HCQ, PPIs alter the acidity of the tumor microenvironment, which induces cytotoxicity of tumor cells, reverses drug resistance, and reduces cancer metastasis (Walsh et al., 2015). PPIs increase the extracellular $\mathrm{pH}$ and acidify the cytosol; as such PPIs can direct chemotherapy agents such as doxorubicin to the nucleus (Luciani et al., 2004; Schwartz et al., 2017). In vivo studies demonstrate that PPIs, such as omeprazole and lansoprazole, enhance tumor sensitivity to cisplatin and paclitaxel (Luciani et al., 2004; Azzarito et al., 2015). The significance of $\mathrm{pH}$ effects in tumor cell homeostasis has been illustrated with PPI single treatments and in combination therapy, which both inhibited tumor proliferation and had a dose-dependent apoptotic-like cytotoxicity (De Milito et al., 2007, 2010; Canitano et al., 2016; Federici et al., 2016; Iessi et al., 2017; Lugini et al., 2017). The importance of $\mathrm{pH}$ alteration in cancer therapeutics is also highlighted when studies utilized a seemingly simple alkaline supplementation alone in murine melanoma and prostate adenocarcinoma that inhibited tumor cell growth and progression (Azzarito et al., 2016; Astigiano et al., 2017). Furthermore, exosome trafficking such as cellular-content release and cell-to-cell transmission is a well-known delivery mechanism in tumor malignancy. Pretreatment with PPIs or even buffering the acidic medium led to an inhibition of exosome uptake and release by a variety of cancer types including melanoma cells, colon, breast, prostate, and osteosarcoma (Parolini et al., 2009; Federici et al., 2014; Logozzi et al., 2018).

To further elucidate the role of altering acidity by PPIs in tumor therapy, a study illustrated that inhibiting ATP6L (a

\section{REFERENCES}

Adar, Y., Stark, M., Bram, E. E., Nowak-Sliwinska, P., Van Den Bergh, H., Szewczyk, G., et al. (2012). Imidazoacridinone-dependent lysosomal photodestruction: a pharmacological Trojan horse approach to eradicate subunit of v-ATPase that regulates acidic endolysosomes) or TM9SF4 (a v-ATPase associated protein) with small interfering RNA enhanced the effectiveness of chemotherapy agents in cancer cell lines (You et al., 2009; Lozupone et al., 2015). In addition, autophagy as a survival mechanism to drug-induced cytotoxicity is illustrated by the PPI esomeprazole, which induces autophagy; but inhibition of autophagy increases the cytotoxicity of esomeprazole (Marino et al., 2010, 2012). Furthermore, PPIs increase tumor extracellular microenvironment $\mathrm{pH}$ and correct T-cell dysfunction as well as improve T-cell-based treatment (Calcinotto et al., 2012). Lastly, PPIs are effective in reversing tumor resistance when used in combination with chemotherapy vs. chemotherapy alone in companion animals and clinical studies (Spugnini et al., 2011, 2014; Ferrari et al., 2013; Walsh et al., 2015; Wang et al., 2015; Falcone et al., 2016; Marchetti et al., 2016). These findings further emphasize the significance of $\mathrm{pH}$ in tumors and the therapeutic impact of proton and metabolic regulation in cancer treatment (Gillies et al., 2019; Pillai et al., 2019).

\section{SUMMARY}

The altered tumor microenvironment plays an important role in the development of tumors, their response to therapy, and the development of chemoresistance. As diprotic weak bases, CQ and HCQ not only affect the luminal $\mathrm{pH}$ of acidic organelles (along the endocytic pathway and biosynthetic secretory pathway) but also affect cytosolic $\mathrm{pH}$. Such CQ-and $\mathrm{HCQ}$-induced $\mathrm{pH}$ alterations in various cellular compartments, in a large part, contribute to their ability to overcome chemoresistance. Thus, repurposing FDA-approved CQ and HCQ as adjuvant cancer therapy to overcome chemoresistance is promising. The full spectrum of their effects on $\mathrm{pH}$ changes and tumor microenvironments suggests that larger and more definitive clinical studies of CQ and HCQ as adjuvant cancer therapies are warranted.

\section{AUTHOR CONTRIBUTIONS}

$\mathrm{PH}$ and $\mathrm{XC}$ drafted the manuscript. $\mathrm{PH}$ prepared the figure. $\mathrm{XC}$ and JG edited the manuscript. All authors contributed to the article and approved the submitted version.

\section{FUNDING}

The authors gratefully acknowledge research support received from the National Institute of Mental Health (R01MH100972, R01MH105329, and R01MH119000).

multidrug-resistant cancers. Cell Death Dis. 3:e293. doi: 10.1038/cddis.20 12.30

Adelusi, S. A., and Salako, L. A. (1982). Tissue and blood concentrations of chloroquine following chronic administration in the rat. J. Pharm. Pharmacol. 34, 733-735. doi: 10.1111/j.2042-7158.1982.tb06211.x 
Al-Akra, L., Bae, D. H., Leck, L. Y. W., Richardson, D. R., and Jansson, P. J. (2019). The biochemical and molecular mechanisms involved in the role of tumor micro-environment stress in development of drug resistance. Biochim. Biophys. Acta Gen. Subj. 1863, 1390-1397. doi: 10.1016/j.bbagen.2019.06.007

Al-Akra, L., Bae, D. H., Sahni, S., Huang, M. L. H., Park, K. C., Lane, D. J. R., et al. (2018). Tumor stressors induce two mechanisms of intracellular P-glycoprotein-mediated resistance that are overcome by lysosomal-targeted thiosemicarbazones. J. Biol. Chem. 293, 3562-3587. doi: 10.1074/jbc.m116. 772699

Alfarouk, K. O., Verduzco, D., Rauch, C., Muddathir, A. K., Adil, H. H. B., Elhassan, G. O., et al. (2014). Glycolysis, tumor metabolism, cancer growth and dissemination. A new $\mathrm{pH}$-based etiopathogenic perspective and therapeutic approach to an old cancer question. Oncoscience 1, 777-802. doi: 10.18632/ oncoscience. 109

Amaravadi, R. K., Lippincott-Schwartz, J., Yin, X. M., Weiss, W. A., Takebe, N., Timmer, W., et al. (2011). Principles and current strategies for targeting autophagy for cancer treatment. Clin. Cancer Res. 17, 654-666. doi: 10.1158/ 1078-0432.ccr-10-2634

Appelqvist, H., Waster, P., Kagedal, K., and Ollinger, K. (2013). The lysosome: from waste bag to potential therapeutic target. J. Mol. Cell Biol. 5, 214-226. doi: $10.1093 / \mathrm{jmcb} / \mathrm{mjt} 022$

Astigiano, S., Puglisi, A., Mastracci, L., Fais, S., and Barbieri, O. (2017). Systemic alkalinisation delays prostate cancer cell progression in TRAMP mice. J. Enzyme Inhib. Med. Chem. 32, 363-368. doi: 10.1080/14756366.2016.125 2760

Axelsson, M. A., Karlsson, N. G., Steel, D. M., Ouwendijk, J., Nilsson, T., and Hansson, G. C. (2001). Neutralization of $\mathrm{pH}$ in the Golgi apparatus causes redistribution of glycosyltransferases and changes in the O-glycosylation of mucins. Glycobiology 11, 633-644. doi: 10.1093/glycob/11.8.633

Azzarito, T., Lugini, L., Spugnini, E. P., Canese, R., Gugliotta, A., Fidanza, S., et al. (2016). Effect of modified alkaline supplementation on syngenic melanoma growth in CB57/BL mice. PLoS One 11:e0159763. doi: 10.1371/journal.pone. 0159763

Azzarito, T., Venturi, G., Cesolini, A., and Fais, S. (2015). Lansoprazole induces sensitivity to suboptimal doses of paclitaxel in human melanoma. Cancer Lett. 356, 697-703. doi: 10.1016/j.canlet.2014.10.017

Baghdadi, H. H. (2017). Targeting cancer cells using 3-bromopyruvate for selective cancer treatment. Saud. J. Med. Med. Sci. 5, 9-19. doi: 10.4103/1658-631x. 194253

Bailey, K. M., Wojtkowiak, J. W., Hashim, A. I., and Gillies, R. J. (2012). Targeting the metabolic microenvironment of tumors. Adv. Pharmacol. 65, 63-107. doi: 10.1016/b978-0-12-397927-8.00004-x

Barnard, R. A., Wittenburg, L. A., Amaravadi, R. K., Gustafson, D. L., Thorburn, A., and Thamm, D. H. (2014). Phase I clinical trial and pharmacodynamic evaluation of combination hydroxychloroquine and doxorubicin treatment in pet dogs treated for spontaneously occurring lymphoma. Autophagy 10, 1415-1425. doi: 10.4161/auto.29165

Belizaire, R., and Unanue, E. R. (2009). Targeting proteins to distinct subcellular compartments reveals unique requirements for MHC class I and II presentation. Proc. Natl. Acad. Sci. U.S.A. 106, 17463-17468. doi: 10.1073/pnas. 0908583106

Bjørkøy, G., Lamark, T., Pankiv, S., Øvervatn, A., Brech, A., and Johansen, T. (2009). Monitoring autophagic degradation of p62/SQSTM1. Methods Enzymol. 452, 181-197. doi: 10.1016/s0076-6879(08)03612-4

Boone, B. A., Bahary, N., Zureikat, A. H., Moser, A. J., Normolle, D. P., Wu, W.-C., et al. (2015). Safety and biologic response of pre-operative autophagy inhibition in combination with gemcitabine in patients with pancreatic adenocarcinoma. Ann. Surg. Oncol. 22, 4402-4410. doi: 10.1245/s10434-0154566-4

Boya, P. (2012). Lysosomal function and dysfunction: mechanism and disease. Antioxid. Redox. Signal 17, 766-774. doi: 10.1089/ars.2011. 4405

Boya, P., Gonzalez-Polo, R. A., Casares, N., Perfettini, J. L., Dessen, P., Larochette, N., et al. (2005). Inhibition of macroautophagy triggers apoptosis. Mol. Cell Biol. 25, 1025-1040. doi: 10.1128/mcb.25.3.1025-1040.2005

Briceño, E., Reyes, S., and Sotelo, J. (2003). Therapy of glioblastoma multiforme improved by the antimutagenic chloroquine. Neurosurg. Focus 14:e3.
Bright, N. A., Gratian, M. J., and Luzio, J. P. (2005). Endocytic delivery to lysosomes mediated by concurrent fusion and kissing events in living cells. Curr. Biol. 15, 360-365. doi: 10.1016/j.cub.2005.01.049

Brown, W. J., Constantinescu, E., and Farquhar, M. G. (1984). Redistribution of mannose-6-phosphate receptors induced by tunicamycin and chloroquine. J. Cell Biol. 99, 320-326. doi: 10.1083/jcb.99.1.320

Burikhanov, R., Hebbar, N., Noothi, S. K., Shukla, N., Sledziona, J., Araujo, N., et al. (2017). Chloroquine-inducible Par-4 secretion is essential for tumor Cell apoptosis and inhibition of metastasis. Cell Rep. 18, 508-519. doi: 10.1016/j. celrep.2016.12.051

Calcinotto, A., Filipazzi, P., Grioni, M., Iero, M., De Milito, A., Ricupito, A., et al. (2012). Modulation of microenvironment acidity reverses anergy in human and murine tumor-infiltrating T lymphocytes. Cancer Res. 72, 2746-2756. doi: 10.1158/0008-5472.can-11-1272

Canitano, A., Iessi, E., Spugnini, E. P., Federici, C., and Fais, S. (2016). Proton pump inhibitors induce a caspase-independent antitumor effect against human multiple myeloma. Cancer Lett. 376, 278-283. doi: 10.1016/j.canlet.2016. 04.015

Caporaso, G. L., Gandy, S. E., Buxbaum, J. D., and Greengard, P. (1992). Chloroquine inhibits intracellular degradation but not secretion of Alzheimer beta/A4 amyloid precursor protein. Proc. Natl. Acad. Sci. U.S.A. 89, 2252-2256. doi: $10.1073 /$ pnas.89.6.2252

Cardone, R. A., Casavola, V., and Reshkin, S. J. (2005). The role of disturbed $\mathrm{pH}$ dynamics and the $\mathrm{Na}+\mathrm{H}+$ exchanger in metastasis. Nat. Rev. Cancer 5, 786-795. doi: 10.1038/nrc1713

Carta, S., Lavieri, R., and Rubartelli, A. (2013). Different members of the IL1 Family come out in different ways: DAMPs vs cytokines? Front. Immunol. $4: 123$.

Casey, J. R., Grinstein, S., and Orlowski, J. (2010). Sensors and regulators of intracellular pH. Nat. Rev. Mol. Cell Biol. 11, 50-61. doi: 10.1038/nrm2820

Chanat, E., and Huttner, W. B. (1991). Milieu-induced, selective aggregation of regulated secretory proteins in the trans-Golgi network. J. Cell Biol. 115, 1505-1519. doi: 10.1083/jcb.115.6.1505

Chandler, L. C., Yusuf, I. H., Mcclements, M. E., Barnard, A. R., Maclaren, R. E., and Xue, K. (2020). Immunomodulatory effects of hydroxychloroquine and chloroquine in viral infections and their potential application in retinal gene therapy. Int. J. Mol. Sci. 21:4972. doi: 10.3390/ijms21144972

Chen, D., Xie, J., Fiskesund, R., Dong, W., Liang, X., Lv, J., et al. (2018). Chloroquine modulates antitumor immune response by resetting tumorassociated macrophages toward M1 phenotype. Nat. Commun. 9:873.

Chen, X., Clark, J., Wunderlich, M., Fan, C., Davis, A., Chen, S., et al. (2017). Autophagy is dispensable for Kmt2a/Mll-Mllt3/Af9 AML maintenance and anti-leukemic effect of chloroquine. Autophagy 13, 955-966. doi: 10.1080/ 15548627.2017.1287652

Cheng, Y., Ren, X., Hait, W. N., and Yang, J.-M. (2013). Therapeutic targeting of autophagy in disease: biology and pharmacology. Pharmacol. Rev. 65, 1162 1197. doi: $10.1124 /$ pr.112.007120

Christensen, K. A., Myers, J. T., and Swanson, J. A. (2002). pH-dependent regulation of lysosomal calcium in macrophages. J. Cell Sci. 115, 599-607.

Circu, M., Cardelli, J., Barr, M. P., O’byrne, K., Mills, G., and El-Osta, H. (2017). Modulating lysosomal function through lysosome membrane permeabilization or autophagy suppression restores sensitivity to cisplatin in refractory nonsmall-cell lung cancer cells. PLoS One 12:e0184922. doi: 10.1371/journal.pone. 0184922

Cody, S. H., Dubbin, P. N., Beischer, A. D., Duncan, N. D., Hill, J. S., Kaye, A. H., et al. (1993). Intracellular pH mapping with SNARF-1 and confocal microscopy. I: A quantitative technique for living tissue and isolated cells. Micron 24, 573-580. doi: 10.1016/0968-4328(93)90034- $\mathrm{x}$

Datta, G., Miller, N. M., Afghah, Z., Geiger, J. D., and Chen, X. (2019). HIV-1 gp120 promotes lysosomal exocytosis in human schwann cells. Front. Cell Neurosci. 13:329.

De Duve, C. (2005). The lysosome turns fifty. Nat. Cell Biol. 7, 847-849. doi: 10.1038/ncb0905-847

De Duve, C., De Barsy, T., Poole, B., Trouet, A., Tulkens, P., and Van Hoof, F. (1974). Commentary. Lysosomotropic agents. Biochem. Pharmacol. 23, 24952531.

De Milito, A., Canese, R., Marino, M. L., Borghi, M., Iero, M., Villa, A., et al. (2010). pH-dependent antitumor activity of proton pump inhibitors against 
human melanoma is mediated by inhibition of tumor acidity. Int. J. Cancer 127, 207-219. doi: 10.1002/ijc.25009

De Milito, A., Iessi, E., Logozzi, M., Lozupone, F., Spada, M., Marino, M. L., et al. (2007). Proton pump inhibitors induce apoptosis of human B-cell tumors through a caspase-independent mechanism involving reactive oxygen species. Cancer Res. 67, 5408-5417. doi: 10.1158/0008-5472.can-064095

Deberardinis, R. J., Lum, J. J., Hatzivassiliou, G., and Thompson, C. B. (2008). The biology of cancer: metabolic reprogramming fuels cell growth and proliferation. Cell Metab. 7, 11-20. doi: 10.1016/j.cmet.2007.10.002

Demaurex, N. (2002). pH Homeostasis of cellular organelles. News Physiol. Sci. 17, 1-5. doi: 10.1152/physiologyonline.2002.17.1.1

Dhar, G., Sen, S., and Chaudhuri, G. (2015). Acid gradient across plasma membrane can drive phosphate bond synthesis in cancer cells: acidic tumor milieu as a potential energy source. PLoS One 10:e0124070. doi: 10.1371/journal.pone. 0124070

Dong, X., Wang, Y., Zhou, Y., Wen, J., Wang, S., and Shen, L. (2016). Aquaporin 3 facilitates chemoresistance in gastric cancer cells to cisplatin via autophagy. Cell Death Discov. 2:16087.

Dunmore, B. J., Drake, K. M., Upton, P. D., Toshner, M. R., Aldred, M. A., and Morrell, N. W. (2013). The lysosomal inhibitor, chloroquine, increases cell surface BMPR-II levels and restores BMP9 signalling in endothelial cells harbouring BMPR-II mutations. Hum. Mol. Genet. 22, 3667-3679. doi: 10. 1093/hmg/ddt216

Eng, C. H., Wang, Z., Tkach, D., Toral-Barza, L., Ugwonali, S., Liu, S., et al. (2016). Macroautophagy is dispensable for growth of KRAS mutant tumors and chloroquine efficacy. Proc. Natl. Acad. Sci. U.S.A. 113, 182-187. doi: 10.1073/ pnas. 1515617113

Estes, M. L., Ewing-Wilson, D., Chou, S. M., Mitsumoto, H., Hanson, M., Shirey, E., et al. (1987). Chloroquine neuromyotoxicity. Clinical and pathologic perspective. Am. J. Med. 82, 447-455. doi: 10.1016/0002-9343(87)90444-x

Ewald, S. E., Lee, B. L., Lau, L., Wickliffe, K. E., Shi, G. P., Chapman, H. A., et al. (2008). The ectodomain of Toll-like receptor 9 is cleaved to generate a functional receptor. Nature 456, 658-662. doi: 10.1038/nature 07405

Fadaka, A., Ajiboye, B., Ojo, O., Adewale, O., Olayide, I., and Emuowhochere, R. (2017). Biology of glucose metabolization in cancer cells. J. Oncol. Sci. 3, 45-51. doi: 10.1016/j.jons.2017.06.002

Fais, S. (2010). Proton pump inhibitor-induced tumour cell death by inhibition of a detoxification mechanism. J. Intern. Med. 267, 515-525. doi: 10.1111/j.13652796.2010.02225.x

Fais, S. (2015). Evidence-based support for the use of proton pump inhibitors in cancer therapy. J. Transl. Med. 13:368.

Falcone, R., Roberto, M., D'antonio, C., Romiti, A., Milano, A., Onesti, C. E., et al. (2016). High-doses of proton pump inhibitors in refractory gastro-intestinal cancer: a case series and the state of art. Dig. Liver Dis. 48, 1503-1505. doi: 10.1016/j.dld.2016.08.126

Fassl, A., Brain, C., Abu-Remaileh, M., Stukan, I., Butter, D., Stepien, P., et al. (2020). Increased lysosomal biomass is responsible for the resistance of triplenegative breast cancers to CDK4/6 inhibition. Sci. Adv. 6:eabb2210. doi: 10 . 1126/sciadv.abb2210

Federici, C., Lugini, L., Marino, M. L., Carta, F., Iessi, E., Azzarito, T., et al. (2016). Lansoprazole and carbonic anhydrase IX inhibitors sinergize against human melanoma cells. J. Enzyme Inhib. Med. Chem. 31, 119-125. doi: 10.1080/ 14756366.2016.1177525

Federici, C., Petrucci, F., Caimi, S., Cesolini, A., Logozzi, M., Borghi, M., et al. (2014). Exosome release and low pH belong to a framework of resistance of human melanoma cells to cisplatin. PLoS One 9:e88193. doi: 10.1371/journal. pone. 0088193

Fennelly, C., and Amaravadi, R. K. (2017). Lysosomal biology in cancer. Methods Mol. Biol. 1594, 293-308. doi: 10.1007/978-1-4939-6934-0_19

Ferrari, S., Perut, F., Fagioli, F., Brach Del Prever, A., Meazza, C., Parafioriti, A., et al. (2013). Proton pump inhibitor chemosensitization in human osteosarcoma: from the bench to the patients' bed. J. Transl. Med. 11:268. doi: 10.1186/1479-5876-11-268

Fu, Z., Cheng, X., Kuang, J., Feng, H., Chen, L., Liang, J., et al. (2018). CQ sensitizes human pancreatic cancer cells to gemcitabine through the lysosomal apoptotic pathway via reactive oxygen species. Mol. Oncol. 12, 529-544. doi: 10.1002/ 1878-0261.12179

Gatenby, R. A., Gawlinski, E. T., Gmitro, A. F., Kaylor, B., and Gillies, R. J. (2006). Acid-mediated tumor invasion: a multidisciplinary study. Cancer Res. 66, 5216-5223. doi: 10.1158/0008-5472.can-05-4193

Geisslinger, F., Muller, M., Vollmar, A. M., and Bartel, K. (2020). targeting lysosomes in cancer as promising strategy to overcome chemoresistance-a mini review. Front. Oncol. 10:1156.

Gerweck, L. E., Kozin, S. V., and Stocks, S. J. (1999). The pH partition theory predicts the accumulation and toxicity of doxorubicin in normal and low-pHadapted cells. Br. J. Cancer 79, 838-842. doi: 10.1038/sj.bjc.6690134

Ghosh, P., Dahms, N. M., and Kornfeld, S. (2003). Mannose 6-phosphate receptors: new twists in the tale. Nat. Rev. Mol. Cell Biol. 4, 202-212. doi: 10.1038/nrm1050

Gillies, R. J., Pilot, C., Marunaka, Y., and Fais, S. (2019). Targeting acidity in cancer and diabetes. Biochim. Biophys. Acta Rev. Cancer 1871, 273-280. doi: 10.1016/j.bbcan.2019.01.003

Gotink, K. J., Broxterman, H. J., Labots, M., De Haas, R. R., Dekker, H., Honeywell, R. J., et al. (2011). Lysosomal sequestration of sunitinib: a novel mechanism of drug resistance. Clin. Cancer Res. 17, 7337-7346. doi: 10.1158/1078-0432.ccr11-1667

Gotoff, S. P. (1968). Lymphocytes in congenital immunological deficiency diseases. Clin. Exp. Immunol. 3, 843-856.

Guo, J. Y., Chen, H. Y., Mathew, R., Fan, J., Strohecker, A. M., Karsli-Uzunbas, G., et al. (2011). Activated Ras requires autophagy to maintain oxidative metabolism and tumorigenesis. Genes Dev. 25, 460-470. doi: 10.1101/gad. 2016311

Hakomori, S. (2002). Glycosylation defining cancer malignancy: new wine in an old bottle. Proc. Natl. Acad. Sci. U.S.A. 99:10231. doi: 10.1073/pnas.172380699

Halcrow, P., Datta, G., Ohm, J. E., Soliman, M. L., Chen, X., and Geiger, J. D. (2019a). Role of endolysosomes and $\mathrm{pH}$ in the pathogenesis and treatment of glioblastoma. Cancer Rep. 2:e1177.

Halcrow, P., Khan, N., Datta, G., Ohm, J. E., Chen, X., and Geiger, J. D. (2019b). Importance of measuring endolysosome, cytosolic, and extracellular $\mathrm{pH}$ in understanding the pathogenesis of and possible treatments for glioblastoma multiforme. Cancer Rep. 2:e1193.

Harguindey, S., Henderson, E. S., and Naeher, C. (1979). Effects of systemic acidification of mice with Sarcoma 180. Cancer Res. 39, 4364-4371.

Harguindey, S., Orive, G., Luis Pedraz, J., Paradiso, A., and Reshkin, S. J. (2005). The role of $\mathrm{pH}$ dynamics and the $\mathrm{Na}+\mathrm{H}+$ antiporter in the etiopathogenesis and treatment of cancer. Two faces of the same coin-one single nature. Biochim. Biophys. Acta 1756, 1-24. doi: 10.1016/j.bbcan.2005.06.004

Hashim, A. I., Zhang, X., Wojtkowiak, J. W., Martinez, G. V., and Gillies, R. J. (2011). Imaging pH and metastasis. NMR Biomed. 24, 582-591. doi: 10.1002/ nbm. 1644

Häuselmann, I., and Borsig, L. (2014). Altered tumor-cell glycosylation promotes metastasis. Front. Oncol. 4:28.

Hiebsch, R. R., Raub, T. J., and Wattenberg, B. W. (1991). Primaquine blocks transport by inhibiting the formation of functional transport vesicles. Studies in a cell-free assay of protein transport through the Golgi apparatus. J. Biol. Chem. 266, 20323-20328. doi: 10.1016/s0021-9258(18)54926-7

Higgins, C. F. (2007). Multiple molecular mechanisms for multidrug resistance transporters. Nature 446, 749-757. doi: 10.1038/nature05630

Homewood, C. A., Warhurst, D. C., Peters, W., and Baggaley, V. C. (1972). Lysosomes, $\mathrm{pH}$ and the anti-malarial action of chloroquine. Nature 235, 50-52. doi: 10.1038/235050a0

Hrabeta, J., Belhajova, M., Subrtova, H., Merlos Rodrigo, M. A., Heger, Z., and Eckschlager, T. (2020). Drug sequestration in lysosomes as one of the mechanisms of chemoresistance of cancer cells and the possibilities of its inhibition. Int. J. Mol. Sci. 21:4392. doi: 10.3390/ijms21124392

Hui, L., Ye, Y., Soliman, M. L., Lakpa, K. L., Miller, N. M., Afghah, Z., et al. (2019). Antiretroviral drugs promote amyloidogenesis by de-acidifying endolysosomes. J. Neuroimmune Pharmacol. [Epub ahead of print].

Hulikova, A., and Swietach, P. (2016). Nuclear proton dynamics and interactions with calcium signaling. J. Mol. Cell Cardiol. 96, 26-37. doi: 10.1016/j.yjmcc. 2015.07.003

Huotari, J., and Helenius, A. (2011). Endosome maturation. EMBO J. 30, 34813500. doi: $10.1038 / \mathrm{emboj} .2011 .286$ 
Iessi, E., Logozzi, M., Mizzoni, D., Di Raimo, R., Supuran, C. T., and Fais, S. (2017). Rethinking the combination of proton exchanger inhibitors in cancer therapy. Metabolites 8:2. doi: 10.3390/metabo8010002

Jahreiss, L., Menzies, F. M., and Rubinsztein, D. C. (2008). The itinerary of autophagosomes: from peripheral formation to kiss-and-run fusion with lysosomes. Traffic (Copenh. Den.) 9, 574-587. doi: 10.1111/j.1600-0854.2008. 00701.x

Jang, C. H., Choi, J. H., Byun, M. S., and Jue, D. M. (2006). Chloroquine inhibits production of TNF-alpha, IL-1beta and IL-6 from lipopolysaccharidestimulated human monocytes/macrophages by different modes. Rheumatology (Oxf.) 45, 703-710. doi: 10.1093/rheumatology/kei282

Jansen, G., Barr, H., Kathmann, I., Bunni, M. A., Priest, D. G., Noordhuis, P., et al. (1999). Multiple mechanisms of resistance to polyglutamatable and lipophilic antifolates in mammalian cells: role of increased folylpolyglutamylation, expanded folate pools, and intralysosomal drug sequestration. Mol. Pharmacol. $55,761-769$.

Jass, J. R., Allison, L. M., and Edgar, S. (1994). Monoclonal antibody TKH2 to the cancer-associated epitope sialosyl Tn shows cross-reactivity with variants of normal colorectal goblet cell mucin. Pathology 26, 418-422. doi: 10.1080/ 00313029400169112

Jeong, J. Y., and Jue, D. M. (1997). Chloroquine inhibits processing of tumor necrosis factor in lipopolysaccharide-stimulated RAW 264.7 macrophages. J. Immunol. 158, 4901-4907.

Johnson, D. E., Ostrowski, P., Jaumouille, V., and Grinstein, S. (2016). The position of lysosomes within the cell determines their luminal pH. J. Cell Biol. 212, 677-692. doi: $10.1083 /$ jcb.201507112

Kallunki, T., Olsen, O. D., and Jaattela, M. (2013). Cancer-associated lysosomal changes: friends or foes? Oncogene 32, 1995-2004. doi: 10.1038/onc.2012.292

Kato, Y., Ozawa, S., Miyamoto, C., Maehata, Y., Suzuki, A., Maeda, T., et al. (2013). Acidic extracellular microenvironment and cancer. Cancer Cell Int. 13:89. doi: 10.1186/1475-2867-13-89

Kaufmann, A. M., and Krise, J. P. (2007). Lysosomal sequestration of aminecontaining drugs: analysis and therapeutic implications. J. Pharm. Sci. 96, 729-746. doi: 10.1002/jps.20792

Kazmi, F., Hensley, T., Pope, C., Funk, R. S., Loewen, G. J., Buckley, D. B., et al. (2013). Lysosomal sequestration (trapping) of lipophilic amine (cationic amphiphilic) drugs in immortalized human hepatocytes (Fa2N-4 cells). Drug Metab. Dispos. 41, 897-905. doi: 10.1124/dmd.112.050054

Kellokumpu, S. (2019). Golgi pH, ion and redox homeostasis: how much do they really matter? Front. Cell Dev. Biol. 7:93.

Khan, N., Halcrow, P. W., Lakpa, K. L., Afghah, Z., Miller, N. M., Dowdy, S. F., et al. (2020). Two-pore channels regulate Tat endolysosome escape and Tat-mediated HIV-1 LTR transactivation. FASEB J. 34, 4147-4162. doi: 10.1096/fj.201902 $534 \mathrm{r}$

Khan, N., Lakpa, K. L., Halcrow, P. W., Afghah, Z., Miller, N. M., Geiger, J. D., et al. (2019). BK channels regulate extracellular Tat-mediated HIV-1 LTR transactivation. Sci. Rep. 9:12285.

Kim, E. L., Wüstenberg, R., Rübsam, A., Schmitz-Salue, C., Warnecke, G., Bücker, E.-M., et al. (2010). Chloroquine activates the p53 pathway and induces apoptosis in human glioma cells. Neuro Oncol. 12, 389-400. doi: 10.1093/ neuonc/nop046

Kirkegaard, T., and Jaattela, M. (2009). Lysosomal involvement in cell death and cancer. Biochim. Biophys. Acta 1793, 746-754. doi: 10.1016/j.bbamcr.2008. 09.008

Klionsky, D. J., Abdelmohsen, K., Abe, A., Abedin, M. J., Abeliovich, H., Acevedo Arozena, A., et al. (2016). Guidelines for the use and interpretation of assays for monitoring autophagy (3rd edition). Autophagy 12, $1-222$.

Kokkonen, N., Rivinoja, A., Kauppila, A., Suokas, M., Kellokumpu, I., and Kellokumpu, S. (2004). Defective acidification of intracellular organelles results in aberrant secretion of cathepsin D in cancer cells. J. Biol. Chem. 279, 3998239988. doi: 10.1074/jbc.m406698200

Kuhns, W., Jain, R. K., Matta, K. L., Paulsen, H., Baker, M. A., Geyer, R., et al. (1995). Characterization of a novel mucin sulphotransferase activity synthesizing sulphated O-glycan core 1, 3-sulphate-Gal $\beta 1$-3GalNAc $\alpha-\mathrm{R}$. Glycobiology 5, 689-697. doi: 10.1093/glycob/5.7.689

Kuznik, A., Bencina, M., Svajger, U., Jeras, M., Rozman, B., and Jerala, R. (2011). Mechanism of endosomal TLR inhibition by antimalarial drugs and imidazoquinolines. J. Immunol. 186, 4794-4804. doi: 10.4049/jimmunol. 1000702

Leroy, C., Rigot, J.-M., Leroy, M., Decanter, C., Le Mapihan, K., Parent, A.-S., et al. (2015). Immunosuppressive drugs and fertility. Orph. J. Rare Dis. 10, 136-136.

Li, Y., Cao, F., Li, M., Li, P., Yu, Y., Xiang, L., et al. (2018). Hydroxychloroquine induced lung cancer suppression by enhancing chemo-sensitization and promoting the transition of M2-TAMs to M1-like macrophages. J. Exp. Clin. Cancer Res. 37, 259-259.

Li, Y., Sun, Y., Jing, L., Wang, J., Yan, Y., Feng, Y., et al. (2017). Lysosome inhibitors enhance the chemotherapeutic activity of doxorubicin in HepG2 cells. Chemotherapy 62, 85-93. doi: 10.1159/000448802

Linstedt, A. D., Mehta, A., Suhan, J., Reggio, H., and Hauri, H. P. (1997). Sequence and overexpression of GPP130/GIMPc: evidence for saturable $\mathrm{pH}$-sensitive targeting of a type II early Golgi membrane protein. Mol. Biol. Cell 8, 10731087. doi: $10.1091 / \mathrm{mbc} .8 .6 .1073$

Liu, F., Shang, Y., and Chen, S.-Z. (2014). Chloroquine potentiates the anti-cancer effect of lidamycin on non-small cell lung cancer cells in vitro. Acta Pharmacol. Sin. 35, 645-652. doi: 10.1038/aps.2014.3

Logozzi, M., Mizzoni, D., Angelini, D. F., Di Raimo, R., Falchi, M., Battistini, L., et al. (2018). Microenvironmental pH and exosome levels interplay in human cancer cell lines of different histotypes. Cancers (Basel) 10:370. doi: 10.3390/ cancers 10100370

López-Lázaro, M. (2010). A new view of carcinogenesis and an alternative approach to cancer therapy. Mol. Med. 16, 144-153. doi: 10.2119/molmed.2009.00162

Lotteau, V., Teyton, L., Peleraux, A., Nilsson, T., Karlsson, L., Schmid, S. L., et al. (1990). Intracellular transport of class II MHC molecules directed by invariant chain. Nature 348, 600-605. doi: 10.1038/348600a0

Lozupone, F., Borghi, M., Marzoli, F., Azzarito, T., Matarrese, P., Iessi, E., et al. (2015). TM9SF4 is a novel V-ATPase-interacting protein that modulates tumor $\mathrm{pH}$ alterations associated with drug resistance and invasiveness of colon cancer cells. Oncogene 34, 5163-5174. doi: 10.1038/onc.2014.437

Lozy, F., and Karantza, V. (2012). Autophagy and cancer cell metabolism. Semin Cell Dev. Biol. 23, 395-401. doi: 10.1016/j.semcdb.2012.01.005

Luciani, F., Spada, M., De Milito, A., Molinari, A., Rivoltini, L., Montinaro, A., et al. (2004). Effect of proton pump inhibitor pretreatment on resistance of solid tumors to cytotoxic drugs. J. Natl. Cancer Inst. 96, 1702-1713. doi: 10.1093/jnci/ djh305

Lugini, L., Federici, C., Borghi, M., Azzarito, T., Marino, M. L., Cesolini, A., et al. (2016). Proton pump inhibitors while belonging to the same family of generic drugs show different anti-tumor effect. J. Enzyme Inhib Med. Chem. 31, 538-545. doi: 10.3109/14756366.2015.1046062

Lugini, L., Sciamanna, I., Federici, C., Iessi, E., Spugnini, E. P., and Fais, S. (2017). Antitumor effect of combination of the inhibitors of two new oncotargets: proton pumps and reverse transcriptase. Oncotarget 8, 4147-4155. doi: 10 . 18632/oncotarget.13792

Luzio, J. P., Pryor, P. R., and Bright, N. A. (2007). Lysosomes: fusion and function. Nat. Rev. Mol. Cell Biol. 8, 622-632. doi: 10.1038/nrm2217

Maeda, Y., Ide, T., Koike, M., Uchiyama, Y., and Kinoshita, T. (2008). GPHR is a novel anion channel critical for acidification and functions of the Golgi apparatus. Nat. Cell Biol. 10, 1135-1145. doi: 10.1038/ncb1773

Maeda, Y., and Kinoshita, T. (2010). The acidic environment of the Golgi is critical for glycosylation and transport. Methods Enzymol. 480, 495-510. doi: 10.1016/ s0076-6879(10)80022-9

Marceau, F., Bawolak, M. T., Lodge, R., Bouthillier, J., Gagne-Henley, A., Gaudreault, R. C., et al. (2012). Cation trapping by cellular acidic compartments: beyond the concept of lysosomotropic drugs. Toxicol. Appl. Pharmacol. 259, 1-12. doi: 10.1016/j.taap.2011.12.004

Marchetti, P., Milano, A., D'antonio, C., Romiti, A., Falcone, R., Roberto, M., et al. (2016). Association between proton pump inhibitors and metronomic capecitabine as salvage treatment for patients with advanced gastrointestinal tumors: a randomized Phase II Trial. Clin. Colorectal. Cancer 15, 377-380. doi: 10.1016/j.clcc.2016.06.005

Marino, M. L., Fais, S., Djavaheri-Mergny, M., Villa, A., Meschini, S., Lozupone, F., et al. (2010). Proton pump inhibition induces autophagy as a survival mechanism following oxidative stress in human melanoma cells. Cell Death Dis. 1:e87. doi: 10.1038/cddis.2010.67

Marino, M. L., Pellegrini, P., Di Lernia, G., Djavaheri-Mergny, M., Brnjic, S., Zhang, X., et al. (2012). Autophagy is a protective mechanism for human 
melanoma cells under acidic stress. J. Biol. Chem. 287, 30664-30676. doi: 10.1074/jbc.m112.339127

Marmor, M. F., Kellner, U., Lai, T. Y., Melles, R. B., and Mieler, W. F. (2016). Recommendations on screening for chloroquine and hydroxychloroquine retinopathy (2016 Revision). Ophthalmology 123, 1386-1394. doi: 10.1016/j. ophtha.2016.01.058

Martin, R. E., Marchetti, R. V., Cowan, A. I., Howitt, S. M., Broer, S., and Kirk, K. (2009). Chloroquine transport via the malaria parasite's chloroquine resistance transporter. Science 325, 1680-1682. doi: 10.1126/science.1175667

Masuda, A., Oyamada, M., Nagaoka, T., Tateishi, N., and Takamatsu, T. (1998). Regulation of cytosol-nucleus $\mathrm{pH}$ gradients by $\mathrm{K}+/ \mathrm{H}+$ exchange mechanism in the nuclear envelope of neonatal rat astrocytes. Brain Res. 807, 70-77. doi: 10.1016/s0006-8993(98)00737-9

Mathew, R., Karantza-Wadsworth, V., and White, E. (2007). Role of autophagy in cancer. Nat. Rev. Cancer 7, 961-967.

Matsuo, H., Chevallier, J., Mayran, N., Le Blanc, I., Ferguson, C., Faure, J., et al. (2004). Role of LBPA and Alix in multivesicular liposome formation and endosome organization. Science 303, 531-534. doi: 10.1126/science.1092425

Mauthe, M., Orhon, I., Rocchi, C., Zhou, X., Luhr, M., Hijlkema, K.-J., et al. (2018). Chloroquine inhibits autophagic flux by decreasing autophagosomelysosome fusion. Autophagy 14, 1435-1455. doi: 10.1080/15548627.2018.147 4314

Mcguire, C., Stransky, L., Cotter, K., and Forgac, M. (2017). Regulation of V-ATPase activity. Front. Biosci. (Land. Ed.) 22:609-622.

Meezan, E., Wu, H. C., Black, P. H., and Robbins, P. W. (1969). Comparative studies on the carbohydrate-containing membrane components of normal and virus-transformed mouse fibroblasts. II. Separation of glycoproteins and glycopeptides by sephadex chromatography. Biochemistry 8, 2518-2524. doi: 10.1021/bi00834a039

Mindell, J. A. (2012). Lysosomal acidification mechanisms. Annu. Rev. Physiol. 74, 69-86. doi: 10.1146/annurev-physiol-012110-142317

Moellering, R. E., Black, K. C., Krishnamurty, C., Baggett, B. K., Stafford, P., Rain, M., et al. (2008). Acid treatment of melanoma cells selects for invasive phenotypes. Clin. Exp. Metastasis 25, 411-425. doi: 10.1007/s10585-0089145-7

Morissette, G., Moreau, E. R. C. G., and Marceau, F. (2004). Massive cell vacuolization induced by organic amines such as procainamide. J. Pharmacol. Exp. Ther. 310, 395-406. doi: 10.1124/jpet.104.066084

Munz, C. (2016). Autophagy beyond intracellular MHC class II antigen presentation. Trends Immunol. 37, 755-763. doi: 10.1016/j.it.2016.08.017

Murray, R. Z., and Stow, J. L. (2014). Cytokine secretion in macrophages: SNAREs, rabs, and membrane trafficking. Front. Immunol. 5:538.

Nagata, H., Che, X. F., Miyazawa, K., Tomoda, A., Konishi, M., Ubukata, H., et al. (2011). Rapid decrease of intracellular $\mathrm{pH}$ associated with inhibition of $\mathrm{Na}+\mathrm{H}+$ exchanger precedes apoptotic events in the MNK45 and MNK74 gastric cancer cell lines treated with 2-aminophenoxazine-3-one. Oncol. Rep. 25, 341-346.

Ng, T. C., Majors, A. W., Vijayakumar, S., Baldwin, N. J., Thomas, F. J., Koumoundouros, I., et al. (1989). Human neoplasm $\mathrm{pH}$ and response to radiation therapy: P-31 MR spectroscopy studies in situ. Radiology 170, 875878. doi: 10.1148/radiology.170.3.2916046

Nguyen, A. L., Tan, A. N., and Lavrijsen, A. P. M. (2018). Chloroquine retinopathy. Ned. Tijdschr. Geneeskd 8:163.

Oberhaensli, R. D., Hilton-Jones, D., Bore, P. J., Hands, L. J., Rampling, R. P., and Radda, G. K. (1986). Biochemical investigation of human tumours in vivo with phosphorus-31 magnetic resonance spectroscopy. Lancet 2, 8-11. doi: $10.1016 / \mathrm{s} 0140-6736(86) 92558-4$

Oda, K., and Ikehara, Y. (1985). Weakly basic amines inhibit the proteolytic conversion of proalbumin to serum albumin in cultured rat hepatocytes. Eur. J. Biochem. 152, 605-609. doi: 10.1111/j.1432-1033.1985.tb09238.x

Ohsumi, Y. (2014). Historical landmarks of autophagy research. Cell Res. 24, 9-23. doi: 10.1038/cr.2013.169

Palokangas, H., Ying, M., Vaananen, K., and Saraste, J. (1998). Retrograde transport from the pre-Golgi intermediate compartment and the Golgi complex is affected by the vacuolar H+-ATPase inhibitor bafilomycin A1. Mol. Biol. Cell 9, 3561-3578. doi: 10.1091/mbc.9.12.3561

Panayi, G. S., Neill, W. A., Duthie, J. J., and Mccormick, J. N. (1973). Action of chloroquine phosphate in rheumatoid arthritis. 1. Immunosuppressive effect. Ann. Rheum. Dis. 32, 316-318. doi: 10.1136/ard.32.4.316
Parolini, I., Federici, C., Raggi, C., Lugini, L., Palleschi, S., De Milito, A., et al. (2009). Microenvironmental $\mathrm{pH}$ is a key factor for exosome traffic in tumor cells. J. Biol. Chem. 284, 34211-34222. doi: 10.1074/jbc.m109.041152

Paroutis, P., Touret, N., and Grinstein, S. (2004). The pH of the secretory pathway: measurement, determinants, and regulation. Physiology (Bethesda) 19, 207-215. doi: 10.1152/physiol.00005.2004

Patel, G. M., and Patel, J. D. (2012). Single core osmotic pump (SCOP): development of single layer osmotic controlled release tablet for poorly soluble drug. J. Pharm. Technol. Drug Res. 1:1. doi: 10.7243/2050-120x-1-1

Peixoto, A., Fernandes, E., Gaiteiro, C., Lima, L., Azevedo, R., Soares, J., et al. (2016). Hypoxia enhances the malignant nature of bladder cancer cells and concomitantly antagonizes protein $\mathrm{O}$-glycosylation extension. Oncotarget 7:39.

Persi, E., Duran-Frigola, M., Damaghi, M., Roush, W. R., Aloy, P., Cleveland, J. L., et al. (2018). Systems analysis of intracellular $\mathrm{pH}$ vulnerabilities for cancer therapy. Nat. Commun. 9:2997.

Pillai, S. R., Damaghi, M., Marunaka, Y., Spugnini, E. P., Fais, S., and Gillies, R. J. (2019). Causes, consequences, and therapy of tumors acidosis. Cancer Metas. Rev. 38, 205-222. doi: 10.1007/s10555-019-09792-7

Pilon-Thomas, S., Kodumudi, K. N., El-Kenawi, A. E., Russell, S., Weber, A. M., Luddy, K., et al. (2016). Neutralization of tumor acidity improves antitumor responses to immunotherapy. Cancer Res. 76, 1381-1390. doi: 10.1158/00085472.can-15-1743

Prasad, H., and Rao, R. (2018). Histone deacetylase-mediated regulation of endolysosomal pH. J. Biol. Chem. 293, 6721-6735. doi: 10.1074/jbc.ra118. 002025

Pu, J., Guardia, C. M., Keren-Kaplan, T., and Bonifacino, J. S. (2016). Mechanisms and functions of lysosome positioning. J. Cell Sci. 129, 4329-4339. doi: 10.1242/ jcs. 196287

Puri, S., Bachert, C., Fimmel, C. J., and Linstedt, A. D. (2002). Cycling of early Golgi proteins via the cell surface and endosomes upon lumenal $\mathrm{pH}$ disruption. Traffic 3, 641-653. doi: 10.1034/j.1600-0854.2002.30906.x

Rebecca, V. W., and Amaravadi, R. K. (2016). Emerging strategies to effectively target autophagy in cancer. Oncogene 35, 1-11. doi: 10.1038/onc.2015.99

Relman, A. S. (1972). Metabolic consequences of acid-base disorders. Kidney Int. 1, 347-359. doi: 10.1038/ki.1972.46

Reshkin, S. J., Bellizzi, A., Caldeira, S., Albarani, V., Malanchi, I., Poignee, M., et al. (2000). Na+/H+ exchanger-dependent intracellular alkalinization is an early event in malignant transformation and plays an essential role in the development of subsequent transformation-associated phenotypes. Faseb J. 14, 2185-2197. doi: 10.1096/fj.00-0029com

Reshkin, S. J., Cardone, R. A., and Harguindey, S. (2013). Na+-H+ exchanger, $\mathrm{pH}$ regulation and cancer. Recent Pat. Anticancer Drug Discov. 8, 85-99. doi: 10.2174/1574892811308010085

Rivinoja, A., Hassinen, A., Kokkonen, N., Kauppila, A., and Kellokumpu, S. (2009). Elevated Golgi $\mathrm{pH}$ impairs terminal N-glycosylation by inducing mislocalization of Golgi glycosyltransferases. J. Cell Physiol. 220, 144-154. doi: $10.1002 /$ jcp. 21744

Rivinoja, A., Kokkonen, N., Kellokumpu, I., and Kellokumpu, S. (2006). Elevated Golgi $\mathrm{pH}$ in breast and colorectal cancer cells correlates with the expression of oncofetal carbohydrate T-antigen. J. Cell Physiol. 208, 167-174. doi: 10.1002/ jcp. 20653

Rojas-Puentes, L. L., Gonzalez-Pinedo, M., Crismatt, A., Ortega-Gomez, A., Gamboa-Vignolle, C., Nuñez-Gomez, R., et al. (2013). Phase II randomized, double-blind, placebo-controlled study of whole-brain irradiation with concomitant chloroquine for brain metastases. Radiat. Oncol. (Lond. Engl.) 8, 209-209. doi: 10.1186/1748-717x-8-209

Roos, A., and Boron, W. F. (1981). Intracellular pH. Physiol. Rev. 61, 296-434.

Rosenfeldt, M. T., O’prey, J., Morton, J. P., Nixon, C., Mackay, G., Mrowinska, A., et al. (2013). p53 status determines the role of autophagy in pancreatic tumour development. Nature 504, 296-300. doi: 10.1038/nature 12865

Ruiz, A., Rockfield, S., Taran, N., Haller, E., Engelman, R. W., Flores, I., et al. (2016). Effect of hydroxychloroquine and characterization of autophagy in a mouse model of endometriosis. Cell Death Dis. 7:e2059. doi: 10.1038/cddis.2015.361

Salaroglio, I. C., Gazzano, E., Abdullrahman, A., Mungo, E., Castella, B., AbdElrahman, G., et al. (2018). Increasing intratumor C/EBP- $\beta$ LIP and nitric oxide levels overcome resistance to doxorubicin in triple negative breast cancer. J. Exp. Clin. Cancer Res. 37:286. 
Savarino, A., Boelaert, J. R., Cassone, A., Majori, G., and Cauda, R. (2003). Effects of chloroquine on viral infections: an old drug against today's diseases? Lancet Infect. Dis. 3, 722-727. doi: 10.1016/s1473-3099(03)00806-5

Schlesinger, P. H., Krogstad, D. J., and Herwaldt, B. L. (1988). Antimalarial agents: mechanisms of action. Antimicrob. Agents Chemother. 32, 793-798. doi: 10. 1128/aac.32.6.793

Schmidt, W. K., and Moore, H. P. (1995). Ionic milieu controls the compartmentspecific activation of pro-opiomelanocortin processing in AtT-20 cells. Mol. Biol. Cell 6, 1271-1285. doi: 10.1091/mbc.6.10.1271

Schornack, P. A., and Gillies, R. J. (2003). Contributions of cell metabolism and H+ diffusion to the acidic $\mathrm{pH}$ of tumors. Neoplasia 5, 135-145. doi: 10.1016/s14765586(03)80005-2

Schrezenmeier, E., and Dorner, T. (2020). Mechanisms of action of hydroxychloroquine and chloroquine: implications for rheumatology. Nat. Rev. Rheumatol. 16, 155-166. doi: 10.1038/s41584-020-0372-x

Schwartz, L., Seyfried, T., Alfarouk, K. O., Da Veiga Moreira, J., and Fais, S. (2017). Out of Warburg effect: An effective cancer treatment targeting the tumor specific metabolism and dysregulated $\mathrm{pH}$. Semin Cancer Biol. 43, 134-138. doi: 10.1016/j.semcancer.2017. 01.005

Seebacher, N. A., Richardson, D. R., and Jansson, P. J. (2016). A mechanism for overcoming P-glycoprotein-mediated drug resistance: novel combination therapy that releases stored doxorubicin from lysosomes via lysosomal permeabilization using Dp44mT or DpC. Cell Death Dis. 7:e2510. doi: 10.1038/ cddis. 2016.381

Seksek, O., and Bolard, J. (1996). Nuclear pH gradient in mammalian cells revealed by laser microspectrofluorimetry. J. Cell Sci. 109:257.

Senthebane, D. A., Rowe, A., Thomford, N. E., Shipanga, H., Munro, D., Mazeedi, M., et al. (2017). The role of tumor microenvironment in chemoresistance: to survive, keep your enemies closer. Int. J. Mol. Sci. 18:1586. doi: 10.3390/ ijms 18071586

Sharapova, T. N., Romanova, E. A., Sashchenko, L. P., and Yashin, D. V. (2018). FasL on the surface of Tag7 (PGRP-S)-activated lymphocytes induces necroptosis in HLA-negative tumor cells with the involvement of lysosomes and mitochondria. Biochimie 152, 174-180. doi: 10.1016/j.biochi.2018.07.003

Sironi, J., Aranda, E., Nordstrom, L. U., and Schwartz, E. L. (2019). Lysosome membrane permeabilization and disruption of the molecular target of rapamycin (mTOR)-lysosome interaction are associated with the inhibition of lung cancer cell proliferation by a chloroquinoline analog. Mol. Pharmacol. 95, 127-138. doi: 10.1124/mol.118.113118

Solomon, V. R., and Lee, H. (2009). Chloroquine and its analogs: a new promise of an old drug for effective and safe cancer therapies. Eur. J. Pharmacol. 625, 220-233. doi: 10.1016/j.ejphar.2009.06.063

Sotelo, J., Briceño, E., and López-González, M. A. (2006). Adding chloroquine to conventional treatment for glioblastoma multiforme: a randomized, doubleblind, placebo-controlled trial. Ann. Intern. Med. 144, 337-343. doi: 10.7326/ 0003-4819-144-5-200603070-00008

Spiering, M. J. (2019). Tor comes to the fore in autophagy. J. Biol. Chem. 294, 18519-18520. doi: 10.1074/jbc.cl119.011710

Spugnini, E., and Fais, S. (2017). Proton pump inhibition and cancer therapeutics: a specific tumor targeting or it is a phenomenon secondary to a systemic buffering? Semin Cancer Biol. 43, 111-118. doi: 10.1016/j.semcancer.2017. 01.003

Spugnini, E. P., Baldi, A., Buglioni, S., Carocci, F., De Bazzichini, G. M., Betti, G., et al. (2011). Lansoprazole as a rescue agent in chemoresistant tumors: a phase I/II study in companion animals with spontaneously occurring tumors. J. Transl. Med. 9:221. doi: 10.1186/1479-5876-9-221

Spugnini, E. P., Buglioni, S., Carocci, F., Francesco, M., Vincenzi, B., Fanciulli, M., et al. (2014). High dose lansoprazole combined with metronomic chemotherapy: a phase I/II study in companion animals with spontaneously occurring tumors. J. Transl. Med. 12:225.

Stock, C., Cardone, R. A., Busco, G., Krähling, H., Schwab, A., and Reshkin, S. J. (2008). Protons extruded by NHE1: digestive or glue? Eur. J. Cell Biol. 87, 591-599. doi: 10.1016/j.ejcb.2008.01.007

Sui, X., Chen, R., Wang, Z., Huang, Z., Kong, N., Zhang, M., et al. (2013). Autophagy and chemotherapy resistance: a promising therapeutic target for cancer treatment. Cell Death Dis. 4:e838. doi: 10.1038/cddis.2013.350
Swietach, P., Vaughan-Jones, R. D., Harris, A. L., and Hulikova, A. (2014). The chemistry, physiology and pathology of $\mathrm{pH}$ in cancer. Philos. Transact. R. Soc. Lond. Ser. B Biol. Sci. 369:20130099. doi: 10.1098/rstb.2013.0099

Tang, Z.-H., Chen, X., Wang, Z.-Y., Chai, K., Wang, Y.-F., Xu, X.-H., et al. (2016). Induction of C/EBP homologous protein-mediated apoptosis and autophagy by licochalcone A in non-small cell lung cancer cells. Sci. Rep. 6:26241.

Taylor, M. A., Das, B. C., and Ray, S. K. (2018). Targeting autophagy for combating chemoresistance and radioresistance in glioblastoma. Apoptosis 23, 563-575. doi: 10.1007/s10495-018-1480-9

Taylor, S., Spugnini, E. P., Assaraf, Y. G., Azzarito, T., Rauch, C., and Fais, S. (2015). Microenvironment acidity as a major determinant of tumor chemoresistance: proton pump inhibitors (PPIs) as a novel therapeutic approach. Drug Resist. Updat 23, 69-78. doi: 10.1016/j.drup.2015.08.004

Thews, O., Gassner, B., Kelleher, D. K., Schwerdt, G., and Gekle, M. (2006). Impact of extracellular acidity on the activity of P-glycoprotein and the cytotoxicity of chemotherapeutic drugs. Neoplasia 8, 143-152. doi: 10.1593/neo.05697

Thorens, B., and Vassalli, P. (1986). Chloroquine and ammonium chloride prevent terminal glycosylation of immunoglobulins in plasma cells without affecting secretion. Nature 321, 618-620. doi: 10.1038/321618a0

Trivedi, B., and Danforth, W. H. (1966). Effect of $\mathrm{pH}$ on the kinetics of frog muscle phosphofructokinase. J. Biol. Chem. 241, 4110-4112. doi: 10.1016/ s0021-9258(18)99819-4

Vaupel, P., Kallinowski, F., and Okunieff, P. (1989). Blood flow, oxygen and nutrient supply, and metabolic microenvironment of human tumors: a review. Cancer Res. 49, 6449-6465.

Verbaanderd, C., Maes, H., Schaaf, M. B., Sukhatme, V. P., Pantziarka, P., Sukhatme, V., et al. (2017). Repurposing Drugs in oncology (ReDO)-chloroquine and hydroxychloroquine as anti-cancer agents. Ecancermedicalscience 11:781.

Walsh, M., Fais, S., Spugnini, E. P., Harguindey, S., Abu Izneid, T., Scacco, L., et al. (2015). Proton pump inhibitors for the treatment of cancer in companion animals. J. Exp. Clin. Cancer Res. 34:93.

Wang, B. Y., Zhang, J., Wang, J. L., Sun, S., Wang, Z. H., Wang, L. P., et al. (2015). Intermittent high dose proton pump inhibitor enhances the antitumor effects of chemotherapy in metastatic breast cancer. J. Exp. Clin. Cancer Res. 34:85.

Wang, F., Gomez-Sintes, R., and Boya, P. (2018). Lysosomal membrane permeabilization and cell death. Traffic 19, 918-931. doi: 10.1111/tra. 12613

White, E., and Dipaola, R. S. (2009). The double-edged sword of autophagy modulation in cancer. Clin. Cancer Res. 15, 5308-5316. doi: 10.1158/10780432.ccr-07-5023

Xia, M.-C., Cai, L., Zhang, S., and Zhang, X. (2018). A cell-penetrating ratiometric probe for simultaneous measurement of lysosomal and cytosolic $\mathrm{pH}$ change. Talanta 178, 355-361. doi: 10.1016/j.talanta.2017.09.044

Xu, H., and Ren, D. (2015). Lysosomal physiology. Annu. Rev. Physiol. 77, 57-80. doi: 10.1146/annurev-physiol-021014-071649

$\mathrm{Xu}, \mathrm{R}$, Ji, Z., Xu, C., and Zhu, J. (2018). The clinical value of using chloroquine or hydroxychloroquine as autophagy inhibitors in the treatment of cancers: a systematic review and meta-analysis. Medicine 97, e12912-e12912.

Yamagishi, T., Sahni, S., Sharp, D. M., Arvind, A., Jansson, P. J., and Richardson, D. R. (2013). P-glycoprotein mediates drug resistance via a novel mechanism involving lysosomal sequestration. J. Biol. Chem. 288, 31761-31771. doi: 10. 1074/jbc.m113.514091

Yan, X., Yang, L., Feng, G., Yu, Z., Xiao, M., Cai, W., et al. (2018). Lup20(29)-en-3 $\beta, 28$-di-yl-nitrooxy acetate affects MCF-7 proliferation through the crosstalk between apoptosis and autophagy in mitochondria. Cell Death Dis. 9:241.

Yang, S., Wang, X., Contino, G., Liesa, M., Sahin, E., Ying, H., et al. (2011). Pancreatic cancers require autophagy for tumor growth. Genes Dev. 25, 717729. doi: $10.1101 /$ gad.2016111

Ye, H., Chen, M., Cao, F., Huang, H., Zhan, R., and Zheng, X. (2016). Chloroquine, an autophagy inhibitor, potentiates the radiosensitivity of glioma initiating cells by inhibiting autophagy and activating apoptosis. BMC Neurol. 16:178.

Yogasundaram, H., Hung, W., Paterson, I. D., Sergi, C., and Oudit, G. Y. (2018). Chloroquine-induced cardiomyopathy: a reversible cause of heart failure. ESC Heart Fail. 5, 372-375. doi: 10.1002/ehf2.12276 
Yoon, Y. H., Cho, K. S., Hwang, J. J., Lee, S. J., Choi, J. A., and Koh, J. Y. (2010). Induction of lysosomal dilatation, arrested autophagy, and cell death by chloroquine in cultured ARPE-19 cells. Invest. Ophthalmol. Vis. Sci. 51, 6030-6037. doi: 10.1167/iovs.10-5278

You, H., Jin, J., Shu, H., Yu, B., De Milito, A., Lozupone, F., et al. (2009). Small interfering RNA targeting the subunit ATP6L of proton pump V-ATPase overcomes chemoresistance of breast cancer cells. Cancer Lett. 280, 110-119. doi: 10.1016/j.canlet.2009.02.023

Zhang, M., Kenny, S. J., Ge, L., Xu, K., and Schekman, R. (2015). Translocation of interleukin-1beta into a vesicle intermediate in autophagy-mediated secretion. Elife 4:e11205.

Zheng, H. C. (2017). The molecular mechanisms of chemoresistance in cancers. Oncotarget 8, 59950-59964. doi: 10.18632/oncotarget.19048

Zhitomirsky, B., and Assaraf, Y. G. (2015). Lysosomal sequestration of hydrophobic weak base chemotherapeutics triggers lysosomal biogenesis and lysosomedependent cancer multidrug resistance. Oncotarget 6, 1143-1156. doi: 10. 18632/oncotarget. 2732
Zhitomirsky, B., and Assaraf, Y. G. (2016). Lysosomes as mediators of drug resistance in cancer. Drug Resist. Updat. 24, 23-33. doi: 10.1016/j.drup.2015. 11.004

Zhitomirsky, B., and Assaraf, Y. G. (2017). Lysosomal accumulation of anticancer drugs triggers lysosomal exocytosis. Oncotarget 8, 45117-45132. doi: 10.18632/ oncotarget.15155

Conflict of Interest: The authors declare that the research was conducted in the absence of any commercial or financial relationships that could be construed as a potential conflict of interest.

Copyright (c) 2021 Halcrow, Geiger and Chen. This is an open-access article distributed under the terms of the Creative Commons Attribution License (CC BY).

The use, distribution or reproduction in other forums is permitted, provided the original author(s) and the copyright owner(s) are credited and that the original publication in this journal is cited, in accordance with accepted academic practice. No use, distribution or reproduction is permitted which does not comply with these terms. 